\title{
Biomass waste conversion into low-cost carbon-based materials for supercapacitors: A sustainable approach for the energy scenario.
}

Jessica Chaparro-Garnica ${ }^{a}$, David Salinas-Torres ${ }^{b}$, María José Mostazo-López ${ }^{\mathrm{a}}$, Emilia Morallón $^{b}$, Diego Cazorla-Amorós ${ }^{\mathrm{a}, \text {, }}$

${ }^{a}$ Departamento de Química Inorgánica and Instituto Universitario de Materiales, Universidad de Alicante, Apartado 99, 03080-Alicante, España

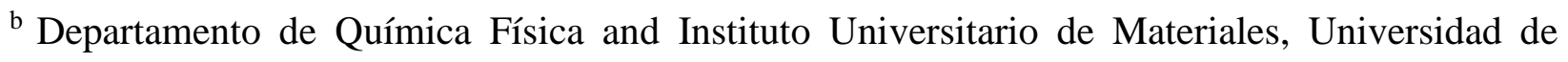
Alicante, Apartado 99, 03080-Alicante, España

*Corresponding Author: cazorla@ua.es. Diego Cazorla-Amorós, Departamento de Química Inorgánica e Instituto Universitario de Materiales, University of Alicante, P.O. Box 99, San Vicente del Raspeig, E03080, Alicante, Spain. Phone number: +34965903946 . 


\begin{abstract}
Biomass upgrading is a promising approach to face the current energy consumption and chemicals production. Lignocellulosic biomass residues have taken the lead in this field. In this study, hemp residue-based activated carbons (ACs) were prepared by $\mathrm{H}_{3} \mathrm{PO}_{4}$-assisted hydrothermal carbonization (HTC) using a low concentration of $\mathrm{H}_{3} \mathrm{PO}_{4}(25$ wt. \%). ACs with a high porosity development were obtained $\left(\mathrm{S}_{\mathrm{BET}}>1200 \mathrm{~m}^{2} \mathrm{~g}^{-1}\right)$, and they were subsequently functionalized with nitrogen groups using mild conditions. As-synthesized ACs were also heat-treated to enhance the electrical conductivity, improving the electrochemical performance. As a proof of concept, electrochemical capacitors (ECs) based on as-prepared ACs in aqueous and organic electrolytes, showing energy densities comparable to those of a capacitor based on an AC used in commercial capacitors. The most attractive outcome of this study is the straightforward, cost-effective, and sustainable methodology to prepare high added-value functional ACs with great potential for energy and environmental applications.
\end{abstract}

Keywords: hydrothermal carbonization, biomass waste, phosphoric acid, nitrogen doping, activated carbon, supercapacitor. 


\section{Introduction}

The humankind can suffer severe health problems because the current contamination levels are continuously rising. Therefore, a great effort must be carried out to reduce them. One of the largest sources of contamination results from the use of fossil fuels for most of the energy production. Lignocellulosic biomass can be considered as a sustainable alternative to the use of fossil fuels because biomass is a natural, abundant, and renewable resource that can be an important contribution to the renewable energy mix. Moreover, it is the only sustainable and reliable carboncontaining source for the industry, which could lead to the conversion of this lignocellulosic biomass into biofuels, energy and a wide range of carbon-based chemical products of high added value [1-6]. There are numerous processes (chemical, thermal, physical, etc.) to convert biomass into high added-value products [7]. These are used as a platform to produce chemicals for several industrial applications such as cosmetics, food additives, plastics, and so on [8-12].

Biomass processing is mainly addressed to obtain products in both the liquid and gas phases. Further benefits could be achieved by also considering the solid phase, which is usually discarded. Some decomposition processes of biomass can generate a solid residue, so-called biochar, from which outstanding carbon materials can be developed [13-15]. Thus, an approach to use lignocellulosic biomass in the production of carbon materials paves the way towards the optimization of biomass upgrading. In this sense, there are several well-known processes to prepare biomass-based carbon materials, being the hydrothermal carbonization (HTC) in the spotlight [16-18]. The HTC is carried out at low temperatures $\left(\sim 200^{\circ} \mathrm{C}\right)$ and self-generated pressure using a close-up vessel, and different biomass precursors can be used. All these aspects make HTC a promising alternative from the industrial viewpoint to produce low-cost highperforming biomass-based carbon materials. They have been applied in important areas such as 
catalysis, adsorption, energy generation, and storage devices, etc. [19-21]. However, the low porosity of the resulting biochars implies the use of a subsequent activation step to develop their porosity [22-25].

The use of biomass-derived carbon materials in energy storage devices, more specifically supercapacitors (SC), has received great attention. The performance of these devices depends, to a great extent, on the design and development of carbon materials used as electrodes. In this context, the carbon electrode must fulfil some features such as high surface area, suitable porosity, high conductivity, high electrochemical stability, and tuneable surface chemistry, among others [26-31]. Besides, the cost should also be considered since it is one of the more important contribution to the SC price. Among the chemical activating agents commonly used to prepare biomass-based carbon materials, $\mathrm{H}_{3} \mathrm{PO}_{4}$ favors aromatization and condensation reactions and can lead to micro-mesoporous carbon materials [18,32-35]. Additionally, a positive aspect of this activation method is its lower polluting effect compared to other chemical activating agents; moreover, $\mathrm{H}_{3} \mathrm{PO}_{4}$ can be reused after recovering it during the washing step. Unfortunately, the main disadvantage of $\mathrm{H}_{3} \mathrm{PO}_{4}$ activation lies in increasing the cost of production as a consequence of a large number of washing steps and the need for recovering the high $\mathrm{H}_{3} \mathrm{PO}_{4}$ concentration necessary for the activation. An interesting approach to increase the yield and reduce the cost of the conventional $\mathrm{H}_{3} \mathrm{PO}_{4}$ activation of biomass, which uses a high concentration of $\mathrm{H}_{3} \mathrm{PO}_{4}$, is the combination of $\mathrm{HTC}$ and $\mathrm{H}_{3} \mathrm{PO}_{4}$ activation. Previous studies have demonstrated that $\mathrm{H}_{3} \mathrm{PO}_{4}$ assisted HTC can offer an interesting route in the synthesis of highly porous carbon materials, improving the impregnation of the biomass precursor and producing higher yields and better porosity development while using low concentration $\mathrm{H}_{3} \mathrm{PO}_{4}$ solutions. [18,36-38]. 
Surface chemistry is another important feature that determines the stability of the carbon electrode. Surface functional groups may increase the reactivity with the electrolyte, which results in the degradation of the carbon electrode; however, other surface functionalities display a stabilizing effect $[39,40]$. Recent studies have demonstrated that specific nitrogen groups can modify the wettability, conductivity, and electrochemical stability of the material $[39,41-45]$. Hence, the use of $\mathrm{N}$-containing precursors or post-treatment procedures to incorporate $\mathrm{N}$ functionalities is an alternative to improve carbon materials for SC applications [46,47]. However, some post-treatment methods use toxic gases or the textural properties of the activated carbon are significantly modified $[45,48]$. Then, the chemical modification using a treatment with nitrogencontaining compounds, which does not damage the porous texture under easy operation and mild temperature conditions is desirable $[43,45]$.

Considering all the above-mentioned aspects, in the present work, we focused on the preparation of low-cost biomass-derived carbon materials by $\mathrm{H}_{3} \mathrm{PO}_{4}$-assisted $\mathrm{HTC}$ and subsequent $\mathrm{N}$-doping using mild conditions. This protocol is a sustainable route to obtain high-performing biomass-based carbon materials for their use as electrodes in supercapacitors. In this study, hemp residue was utilized as a biomass source and diluted $\mathrm{H}_{3} \mathrm{PO}_{4}$ solutions $(25 \%$ w/w) as activating agent. As-synthesized carbon materials have been modified using heat treatment and mild organic reactions to introduce nitrogen groups, showing a remarkable improvement in their electrochemical performance. Furthermore, a commercial activated carbon (WV-A1100, MeadWestvaco. Corp.) obtained from wood by conventional $\mathrm{H}_{3} \mathrm{PO}_{4}$ activation was used for comparison purposes. The most attractive point of this eco-friendly approach is the straightforward methodology for preparing low cost biomass-based carbon materials with electrochemical 
performance as a supercapacitor electrode similar to that of an activated carbon used in commercial supercapacitors (YP-50F, Kuraray Chemical Co.).

\section{Experimental}

\subsection{Activated hydrothermal carbon and thermal treatment}

An activated carbon was prepared by $\mathrm{H}_{3} \mathrm{PO}_{4}$-assisted HTC using biomass precursor (hemp residue) using a methodology similar to that previously described [18]. The synthesis procedure was as follows: $1 \mathrm{~g}$ of precursor and $4 \mathrm{~g}$ of a $25 \mathrm{wt}$. \% aqueous solution of $\mathrm{H}_{3} \mathrm{PO}_{4}$ were placed into a $50 \mathrm{~mL}$ Teflon-lined stainless-steel autoclave. Then, the autoclave was closed and heated at 200 ${ }^{\circ} \mathrm{C}$ for $24 \mathrm{~h}$. The resulting hydrochar was heated at $450{ }^{\circ} \mathrm{C}$ under a constant flow of $\mathrm{N}_{2}(50 \mathrm{~mL}$ $\min ^{-1}$ ) for $2 \mathrm{~h}$ in a tubular oven. As-synthesised activated carbon was washed with distilled water at $65^{\circ} \mathrm{C}$ to remove the activating agent. Finally, the activated carbon was dried at $110{ }^{\circ} \mathrm{C}$ for $12 \mathrm{~h}$. The activated carbon was named as HTC_HR_450 (HR refers to hemp residue). The yield of the AC preparation is $40 \mathrm{wt} \%$. A commercial activated carbon (WV-A1100, MeadWestvaco Corp.), which is prepared by conventional chemical activation with $\mathrm{H}_{3} \mathrm{PO}_{4}$ using wood as precursor, was used for comparison purposes. In addition, both activated carbons mentioned above were heattreated at $900{ }^{\circ} \mathrm{C}$ for 15 min under $\mathrm{N}_{2}$ atmosphere $\left(80 \mathrm{~mL} \mathrm{~min}^{-1}\right)$. The resulting samples were named as HTC_HR_450_TT and WV-A1100_TT, respectively.

\subsection{Nitrogen chemical functionalization of activated carbons}

The modification of the surface chemistry of all activated carbons through $\mathrm{N}$ doping, was carried out using an organic reaction under mild temperature conditions. This procedure is briefly described below [44]: (i) $45 \mathrm{~mL}$ of $2 \mathrm{M} \mathrm{NH}_{4} \mathrm{NO}_{3} / \mathrm{DMF}$ solution were prepared in a round bottom flask. Then, $300 \mathrm{mg}$ of activated carbon were added under constant stirring. (ii) A volume of 45 $\mathrm{mL}$ of pyridine was added dropwise at room temperature. (iii) The resulting mixture was kept 
under stirring at $70{ }^{\circ} \mathrm{C}$ for $65 \mathrm{~h}$. The $\mathrm{N}$-containing activated carbons were washed with abundant water and $\mathrm{EtOH}$, filtered and dried at $110{ }^{\circ} \mathrm{C}$ for $12 \mathrm{~h}$. The functionalized samples were denoted by adding an "N" to the previously mentioned nomenclature of the samples.

\subsection{Physicochemical characterization of activated carbons}

The porous texture of the activated carbons was determined by the physical adsorption of $\mathrm{N}_{2}$ at $-196{ }^{\circ} \mathrm{C}$ by using an automatic adsorption system (Autosorb-6B, Quantachrome). The samples were outgassed at $200{ }^{\circ} \mathrm{C}$ for $6 \mathrm{~h}$. The apparent surface area was calculated using the BrunauerEmmett-Teller (BET) method in the relative pressure range of 0.05 to 0.17 . The total micropore volume $\left(\mathrm{V}_{\mathrm{DR}} \mathrm{N}_{2}\right)$ was determined by the application of the Dubinin-Radushkevich (DR) equation to the $\mathrm{N}_{2}$ adsorption isotherm at $-196{ }^{\circ} \mathrm{C}$. Mesopore volume was determined by calculating the difference between the volume of $\mathrm{N}_{2}$ adsorbed at a relative pressure of 0.95 and the volume of micropores present in the samples [49]. The pore size distribution was determined from the $\mathrm{N}_{2}$ adsorption isotherms applying the 2D-NLDFT heterogeneous surface model using SAIEUS software [50] (available online at http://www.nldft.com/).

The proximate analysis of all activated carbons was performed in a thermogravimetric analyzer (TA instruments, SDT 2960). All samples were heated up to $120^{\circ} \mathrm{C}$ with a heating rate of $20^{\circ} \mathrm{C}$ $\mathrm{min}^{-1}$ using a $\mathrm{N}_{2}$ flow of $100 \mathrm{~mL} \mathrm{~min}^{-1}$ for $30 \mathrm{~min}$ and then heated at $800{ }^{\circ} \mathrm{C}$. At this point, moisture and volatile compound content were quantified in each sample. Finally, the gas flow was changed to air and ashes and fixed carbon content was determined [51].

Regarding the surface chemistry, temperature programmed desorption (TPD) measurements were performed in a DSC-TGA equipment (TA instruments, SDT Q600) coupled to a mass spectrometer (Thermostar, Balzers, BSC 200). All samples were heated at $950{ }^{\circ} \mathrm{C}$ with a heating rate of $20^{\circ} \mathrm{C} \mathrm{min}^{-1}$ under a helium flow rate of $100 \mathrm{~mL} \mathrm{~min}{ }^{-1}$. X-ray photoelectron spectroscopy 
(XPS) experiments were performed in a spectrometer (VG-Microtech Multilab 3000). N1s spectra were deconvoluted by fitting with a combination of Gaussian functions with a Lorentzian component. The FWHM of the peaks was fixed between 1.4 and $1.7 \mathrm{eV}$ and a Shirley line was used to estimate the background signal.

\subsection{Electrochemical characterization}

\subsection{1 $\quad$ Three electrode cell configuration}

Disc-shaped electrodes were prepared by mixing activated carbon (AC), acetylene black (AB) and binder (PTFE), in a ratio of 90:5:5 wt. \%. The as-prepared electrode was pressed onto a titanium mesh (current collector) at 2 tons for 2 minutes to ensure a homogeneous thickness. The weight and the diameter of the electrode were approximately $6 \mathrm{mg}$ and $10 \mathrm{~mm}$, respectively. Before the electrochemical measurements, the electrodes were impregnated with sulphuric acid aqueous solution $\left(1 \mathrm{M} \mathrm{H}_{2} \mathrm{SO}_{4}\right)$ for 1 day.

The electrochemical characterization of the electrodes was performed with a multichannel potentiostat (VSP Biologic) in a standard three-electrode cell using an $\mathrm{Ag} / \mathrm{AgCl}(3 \mathrm{M} \mathrm{KCl})$ reference electrode and a platinum wire as the counter electrode. The electrochemical behavior was evaluated by cyclic voltammetry at different scan rates and capacitance values were calculated from the voltammogram.

\subsubsection{Two electrode cell configuration}

Symmetric capacitors were assembled in both aqueous and organic electrolytes using a twoelectrode cell configuration (Swagelok®). The electrodes in aqueous electrolyte were prepared following the same methodology described in section 2.4 .1 with approximately $1.5 \mathrm{mg}$ and a diameter of $5 \mathrm{~mm}$. However, in the case of organic electrolyte the ratio of AC:AB:PTFE was 85:10:5 wt. $\%$ and the weight and the diameter were $1.1 \mathrm{mg}$ and $6 \mathrm{~mm}$, respectively. A conducting 
adhesive was used to join the electrode with the current collector (stainless steel), and then these were strongly pressed against each other separated by a nylon membrane (Teknokroma, pore size: $450 \mathrm{~nm}$ ) for capacitors in aqueous electrolyte and a glass microfiber membrane (Whatman GF/D, thickness: $675 \mu \mathrm{m}$ ) for capacitors in organic electrolyte. The capacitors in organic electrolyte were assembled in an Argon glovebox. All devices were characterized by cyclic voltammetry at different scan rates and galvanostatic charge-discharge (GCD) cycles at different current densities using a multichannel potentiostat (Biologic VSP). Moreover, durability tests of 5000 GCD cycles were performed to evaluate the stability in a potential window of $1.1 \mathrm{~V}$ at $1 \mathrm{~A} \mathrm{~g} \mathrm{~g}^{-1}$ in aqueous electrolyte (1 $\left.\mathrm{M} \mathrm{H}_{2} \mathrm{SO}_{4}\right)$, while supercapacitors in the organic electrolyte (1M TEMA-BF$\left./ \mathrm{PC}\right)$ were assessed in a potential window of $2.5 \mathrm{~V}$ at $1 \mathrm{~A} \mathrm{~g}^{-1}$ using an Arbin SCTS potentiostat. Specific capacitance was referred to the total active mass of the carbon material in each cell following the equation (1).

$$
C=(I \Delta t) /(m \Delta V)
$$

To obtain the capacitor performance, the energy density and the power density were calculated in the same manner as it was reported in previous studies [44]. The energy density ( $\left.\mathrm{E}, \mathrm{Wh} \mathrm{kg}^{-1}\right)$ is determined from the discharge cycle using the following equation (2):

$$
E=\int_{0}^{Q} V d Q
$$

Where $\mathrm{V}$ is the voltage and Q is the stored charge.

Power density ( $\left.\mathrm{P}, \mathrm{W} \mathrm{kg}^{-1}\right)$ is determined using equation (3):

$$
P=\frac{E}{t_{d}}
$$


Where $\mathrm{E}$ is the stored energy and $t_{d}$ is the discharge time (h). In addition, energy efficiency and coulombic efficiency were calculated with equations (4) and (5) respectively:

$$
\begin{gathered}
\text { Energy efficiency }=\frac{E_{c}}{E_{d}} * 100 \\
\text { Coulombic efficiency }=\frac{C_{c}}{C_{d}} * 100
\end{gathered}
$$

Where Ec is the energy stored during the charge process, Ed is the energy stored during the charge process, $\mathrm{Cc}$ is the capacitance of the charge and $\mathrm{Cd}$ the capacitance value obtained from the discharge curve.

\section{Results and discussion}

\subsection{Porous texture and surface chemistry characterization}

Figure 1 shows the adsorption-desorption isotherms of $\mathrm{N}_{2}$ and the pore size distribution of two series of activated carbons. Figures 1a and 1c compiles the results of activated carbons prepared by $\mathrm{H}_{3} \mathrm{PO}_{4}$-assisted $\mathrm{HTC}$ of hemp residue as well as the functionalized counterparts, while the results of a commercial activated carbon (WV-A1100) and its derivatives are plotted in Figures $1 \mathrm{~b}$ and $1 \mathrm{~d}$. The figure also includes for comparison purposes the isotherm for commercial YP50F activated carbon. All isotherms show large $\mathrm{N}_{2}$ uptakes at low relative pressures, which are characteristic of microporous solids (type I isotherm) [49]. Moreover, a hysteresis loop can be seen for the commercial activated carbon (WV-A1100) and its functionalized counterparts, which is related to the presence of mesopores, indicating that these isotherms correspond to the combination of type I and IV isotherms (Figure 1b). The slope of the isotherm at relative pressures above 0.2 and the small hysteresis loop for HTC_HR_450 and HTC_HR_450_N, are due to some mesoporosity contribution (Figure 1a). However, the contribution from mesopores disappears in 
these samples after heat treatment indicating that some material reorganization takes place considering the low activation temperature used [52]. However, for WV-A1100 derived heattreated materials the porosity shrinkage is clear but they still contain significant mesoporosity contribution. Regarding the pore size distributions (PSDs), activated carbons derived from WVA1100 show a bimodal distribution with a first peak at around $1 \mathrm{~nm}$ and a region of pore sizes higher than $2 \mathrm{~nm}$ (see Figure 1d), arising from the presence of mesopores. However, PSDs of activated carbons obtained from the hemp residue only display a peak centered at $1 \mathrm{~nm}$ although the PSD is narrower for the heat treated samples. The PSDs for activated carbons derived from hemp residue are quite similar to that for the commercial YP50F material.
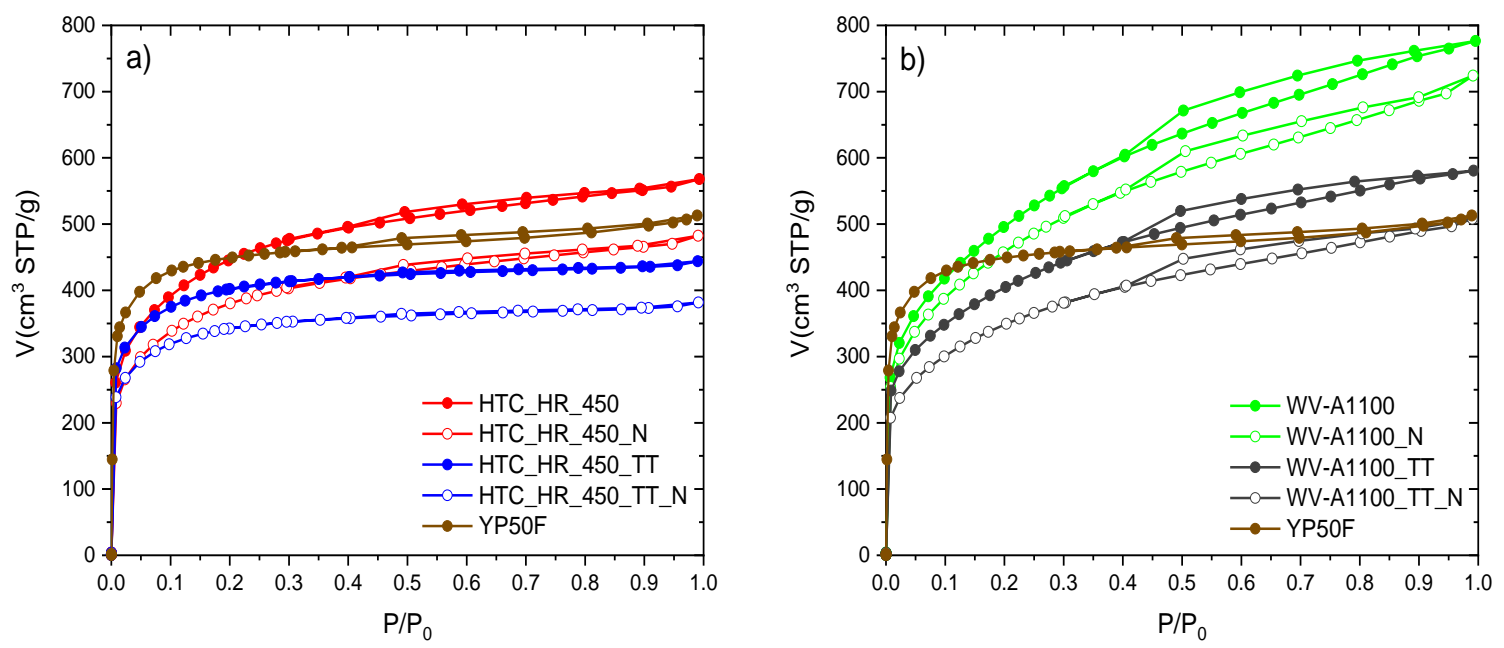

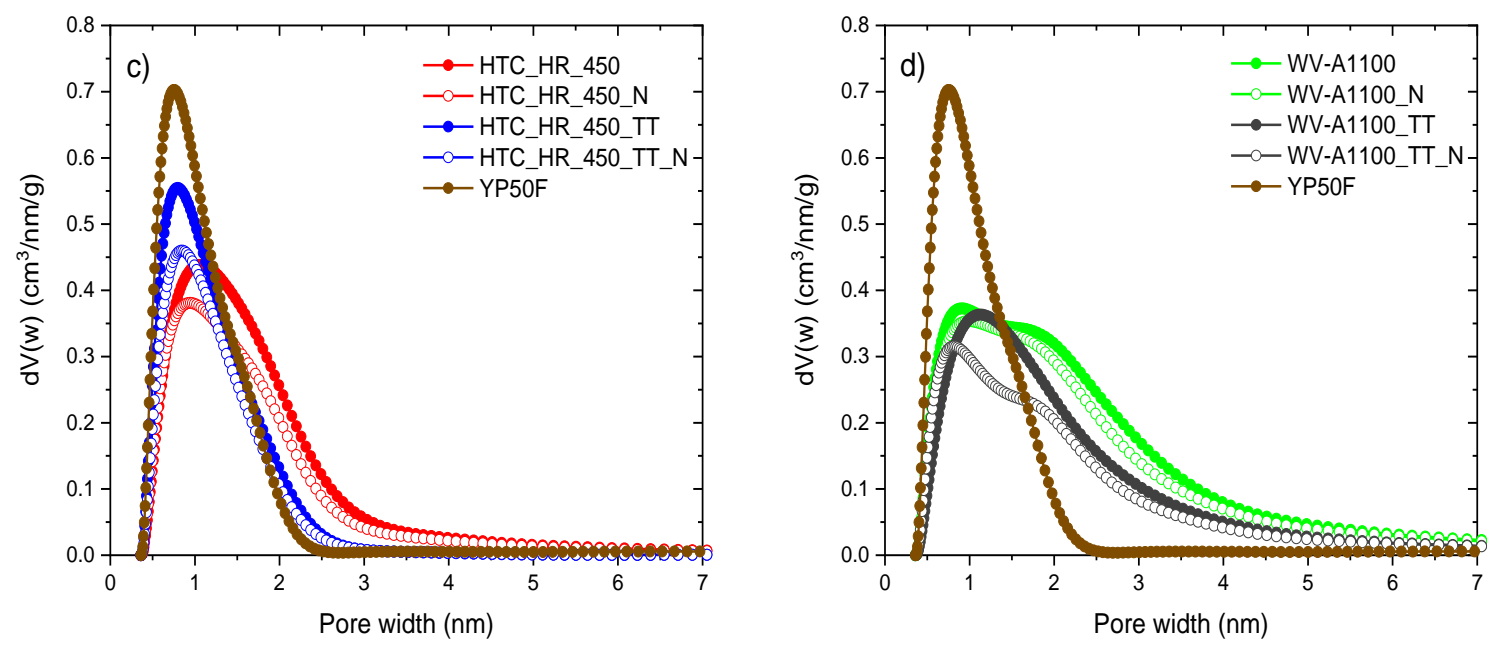

Figure 1. $\mathrm{N}_{2}$ adsorption isotherms at $-196{ }^{\circ} \mathrm{C}$ and pore size distribution for all activated carbons (a, c) activated hydrothermal carbon (HTC_HR_450) and the modified counterparts. (b, d) WVA1100 (commercial) and the modified counterparts.

Table 1 summarizes the porous texture properties of all activated carbons. WV-A1100 has the highest surface area $\left(1800 \mathrm{~m}^{2} \mathrm{~g}^{-1}\right)$ and mesopore volume (Vmeso $\left.\mathrm{N}_{2}\right)$, while the activated carbon prepared by $\mathrm{H}_{3} \mathrm{PO}_{4}$-assisted $\mathrm{HTC}$ has a $\mathrm{S}_{\mathrm{BET}}$ and pore volume values which are close to those of the commercial YP50F sample. It should be highlighted that our synthesis HTC protocol leads to biomass-based activated carbons comparable to those of conventional $\mathrm{H}_{3} \mathrm{PO}_{4}$ activation in terms of porous texture. However, the present protocol used lower concentration of $\mathrm{H}_{3} \mathrm{PO}_{4}(25 \mathrm{wt} \%$ compared to above $50 \mathrm{wt} \%$ typically used), resulting in more cost-effective and environmentally friendly carbon materials. The heat treatment performed on both activated carbons (WV-A1100 and HTC_HR_450) leads to a slight decay in the apparent surface area as a consequence of the shrinkage of the porosity (Table 1). After nitrogen chemical functionalization, some decrease in porosity is observed, which can be mainly attributed to the partial blocking or filling of the porosity by the generation of functional groups [43]. Despite of the nitrogen functionalization treatment, the resulting activated carbons retained more than $90 \%$ of the original porous texture in agreement with a previous study [44]. 
Table 1. Porous texture and surface chemistry for the activated carbons.

\begin{tabular}{|c|c|c|c|c|c|c|c|c|}
\hline Sample & $\begin{array}{c}S_{B E T} \\
\left(m^{2} g^{-1}\right)\end{array}$ & $\begin{array}{c}V_{D R} \\
{ }^{3} \\
\left(\mathrm{~cm}^{-g^{-1}}\right.\end{array}$ & $\begin{array}{c}\mathrm{V}_{\text {meso }} \\
\left(\mathrm{cm}^{3} \mathrm{~g}^{-1}\right)\end{array}$ & $\begin{array}{c}\mathbf{N}_{\text {XPS }} \\
(\text { at. \%) }\end{array}$ & $\begin{array}{c}P_{\text {XPS }} \\
(\text { at. \%) }\end{array}$ & 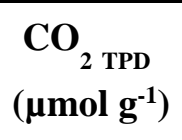 & 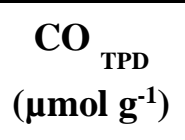 & $\mathbf{O}_{\text {TPD }}\left(\mu \mathrm{mol} \mathrm{g^{-1 } )}\right.$ \\
\hline HTC_HR_450 & 1630 & 0.78 & 0.08 & - & 0.29 & 320 & 2370 & 3010 \\
\hline HTC_HR_450_N & 1400 & 0.66 & 0.07 & 1.8 & 0.15 & 470 & 1620 & 2560 \\
\hline HTC_HR_450_TT & 1463 & 0.67 & 0.01 & - & 0.44 & 121 & 1278 & 1520 \\
\hline HTC_HR_450_TT_N & 1243 & 0.57 & 0.02 & 1.7 & 0.46 & 130 & 1033 & 1293 \\
\hline WV-A1100 & 1800 & 0.91 & 0.27 & - & 0.80 & 680 & 530 & 1890 \\
\hline WV-A1100_N & 1670 & 0.84 & 0.24 & 1.6 & 0.52 & 630 & 420 & 1680 \\
\hline WV-A1100_TT & 1460 & 0.73 & 0.17 & - & 0.58 & 90 & 950 & 1130 \\
\hline WV-A1100_TT_N & 1270 & 0.62 & 0.14 & 1.9 & 0.48 & 310 & 150 & 770 \\
\hline YP50F & 1680 & 0.73 & 0.05 & - & - & 160 & 520 & 840 \\
\hline
\end{tabular}

From the proximate analysis of all activated carbons (see Table 2), it was observed that activated carbon prepared by $\mathrm{H}_{3} \mathrm{PO}_{4}$-assisted $\mathrm{HTC}$ displayed slightly higher percentage of fixed carbon and lower ash content than WV-A1100. This is attributed to the more improved impregnation of the activating agent during the hydrothermal treatment that makes the activation process more efficient. This also results in higher yields than those obtained from conventional $\mathrm{H}_{3} \mathrm{PO}_{4}$ activation of biomass residues [18].

The heat treatment up to $900{ }^{\circ} \mathrm{C}$ carried out on both activated carbons (samples HTC_HR_450_TT and WV-A1100_TT) resulted in a decrease of volatile matter, as expected due to the much lower temperature used during the activation $\left(450{ }^{\circ} \mathrm{C}\right.$ versus $\left.900{ }^{\circ} \mathrm{C}\right)$. The heat treatment produces further carbonization and structural changes in the material. The increase in the amount of fixed carbon indicates that activated carbons with higher aromaticity and structural order are obtained. 
Regarding the $\mathrm{N}$-functionalized samples, it can be seen that the amount of volatile matter increases due to the introduction of nitrogen functional groups on the surface of the activated carbon. The ash content in the as prepared AC could be due to the presence of phosphorus containing groups, which are incorporated into the activated carbon during the activation step [18], although other inorganic compounds present in the biomass precursor cannot be ruled out. Interestingly, the nitrogen functionalization method used produces an important decrease in the ash content, especially in the non-heat treated activated carbons.

Table 2. Proximate analysis for the activated carbons

\begin{tabular}{cccc}
\hline Sample & Volatiles (wt. \%)* & Fixed carbon (wt. \%) & Ash (wt. \%)* \\
\hline HTC_HR_450 & 9.3 & 88.4 & 2.3 \\
HTC_HR_450_N & 12.7 & 87.2 & 0.1 \\
HTC_HR_450_TT & 3.1 & 94.0 & 2.9 \\
HTC_HR_450_TT_N & 6.6 & 91.3 & 2.1 \\
WV-A1100 & 9.9 & 85.3 & 4.7 \\
WV-A1100_N & 13.8 & 85.5 & 0.7 \\
WV-A1100_TT & 2.3 & 93.0 & 4.7 \\
WV-A1100_TT_N & 8.2 & 90.1 & 1.7 \\
\hline
\end{tabular}

* Dry basis.

Concerning the surface chemistry, Figure 2 shows the XPS spectra of the N 1s of all functionalized activated carbons, which are deconvoluted into several peaks related to the different nitrogen groups. From the XPS data (see Table 1), it was observed a similar nitrogen content (approx. 2 at. \%) in all activated carbons after the chemical functionalization under mild conditions. Additionally, Table 1 compiles the quantification of oxygen groups from TPD measurements of all activated carbons, which show a decrease in the amount of oxygen after functionalization treatment due to the reaction of these surface oxygen groups with the nitrogen reactants. The main decrease in oxygen functional groups occurs mainly in CO-evolving groups (phenol and carbonyl groups) (see Figure 3). The anchorage of nitrogen groups by consumption of oxygen functional groups has been demonstrated in previous works $[41,43,44]$. The 
chemisorption of pyridine and DMF under these experimental conditions is negligible and was confirmed in previous work by immersing the pristine carbon in pyridine and washing using analogous processes to those performed for the doping of the ACs [44]. The results indicate that the $\mathrm{N}$ moieties detected on the carbon materials are consequence of organic reactions between the carbon material and the nitrogen reactants through conversion of $\mathrm{CO}$ evolving groups.
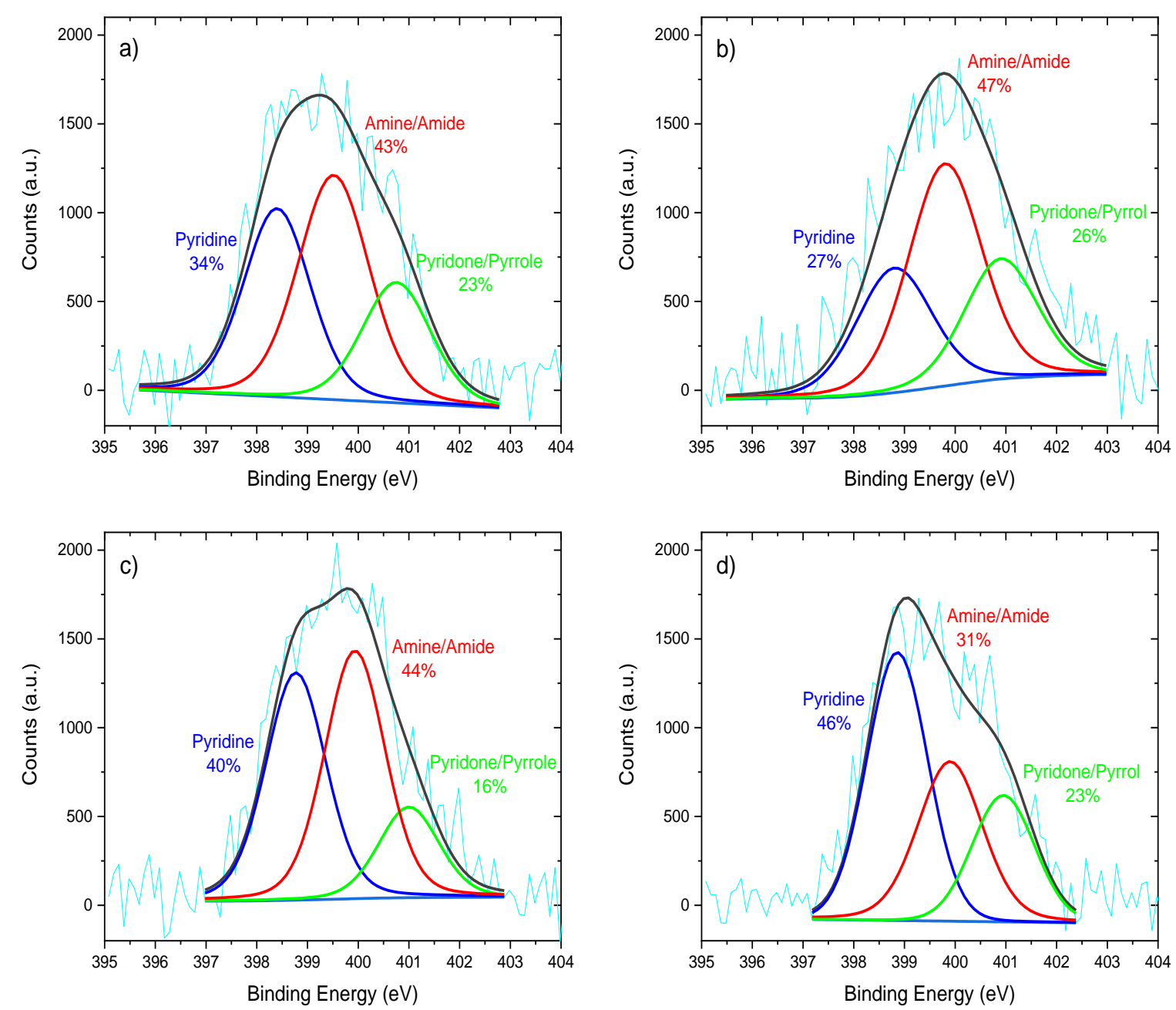

Figure 2. N1s XPS spectra of activated carbon a) HTC_HR_450_N b) HTC_HR_450_TT_N c) WV-A1100_N and d) WV-A1100_TT_N.

The assignment of the deconvoluted peaks to the different nitrogen functional groups was carried out according to previous studies $[43,44,53-55]$. The N 1s spectrum of HTC_HR_450_N was deconvoluted into three peaks at 398.4 and $400.8 \mathrm{eV}$, assigned to imines/pyridines, and 
pyridone/pyrrole groups, respectively, and the last one at $399.5 \mathrm{eV}$ assigned to amines, amides or cyclic amides [43,53-57]. WV-A1100_N displayed the same contributions as HTC_HR_450_N but their peak positions are slightly shifted to higher binding energies. Concerning the heat-treated samples, both HTC_HR_450_TT_N and WV-A1100_TT_N, were also deconvoluted into three peaks. HTC_HR_450_TT_N presents two similar peaks at 398.8 and $399.8 \mathrm{eV}$ associated to pyridine/imine and amines, amides or cyclic amides, respectively and a peak at higher binding energy $(400.8 \mathrm{eV})$ attributed to pyridone/pyrrole groups.

TPD data in Table 1 shows that $\mathrm{N}$ functionalization occurs through reaction with oxygen functional groups, mainly with CO-type groups which are the most abundant. Figure 3 shows the $\mathrm{CO}_{2}$ and $\mathrm{CO}$ TPD profiles for all activated carbons. It can be seen that HTC_HR_450 is rich in phenol groups, which evolve as $\mathrm{CO}$ between $600{ }^{\circ} \mathrm{C}$ and $700{ }^{\circ} \mathrm{C}$, and in carbonyl groups that are desorbed at around $800{ }^{\circ} \mathrm{C}$ [58-60]. Moreover, CO-evolving groups at lower temperatures $(<600$ ${ }^{\circ} \mathrm{C}$ ) were observed, which can be attributed to the presence of anhydride groups that decompose forming one $\mathrm{CO}$ and one $\mathrm{CO}_{2}$ molecule. This is in agreement with the $\mathrm{CO}_{2}$ profile of HTC_HR_450 that shows $\mathrm{CO}_{2}$ desorption between $400-600{ }^{\circ} \mathrm{C}$ [58-60]. In agreement with the heat treatment temperatures used, there is a small $\mathrm{CO}_{2}$ desorption between $200{ }^{\circ} \mathrm{C}$ and $400{ }^{\circ} \mathrm{C}$ that can be assigned to the presence of carboxylic groups [58-60].

After functionalization (HTC_HR_450_N sample), the evolution of CO decreased significantly at temperatures over $600{ }^{\circ} \mathrm{C}$ revealing that phenol and carbonyl groups were consumed during the functionalization reactions. It confirms that substitution and condensation reactions occur through surface oxygen groups giving rise to the generation of nitrogen groups $[41,43,44]$. Amine groups can be generated from phenol groups, while the formation of pyrrole, pyridine and imines involves carbonyl groups. Additionally, from the imines, condensation reactions with aldehydes or ketones 
can be produced, thus forming aromatic nitrogen heterocycles, which can be pyrroles or pyridines depending on the distance at which the carbonyl groups are found $[41,43,44]$. Phosphoruscontaining groups can also contribute to the nitrogen functionalization through similar reactions, what is in agreement with the observed decrease in ash content in the functionalized samples (Table 2). Similar conclusions can be deduced for WV-A1100 sample although the changes in the TPD are not so important as with HTC_HR_450 sample because the oxygen content is smaller (see Table 1).
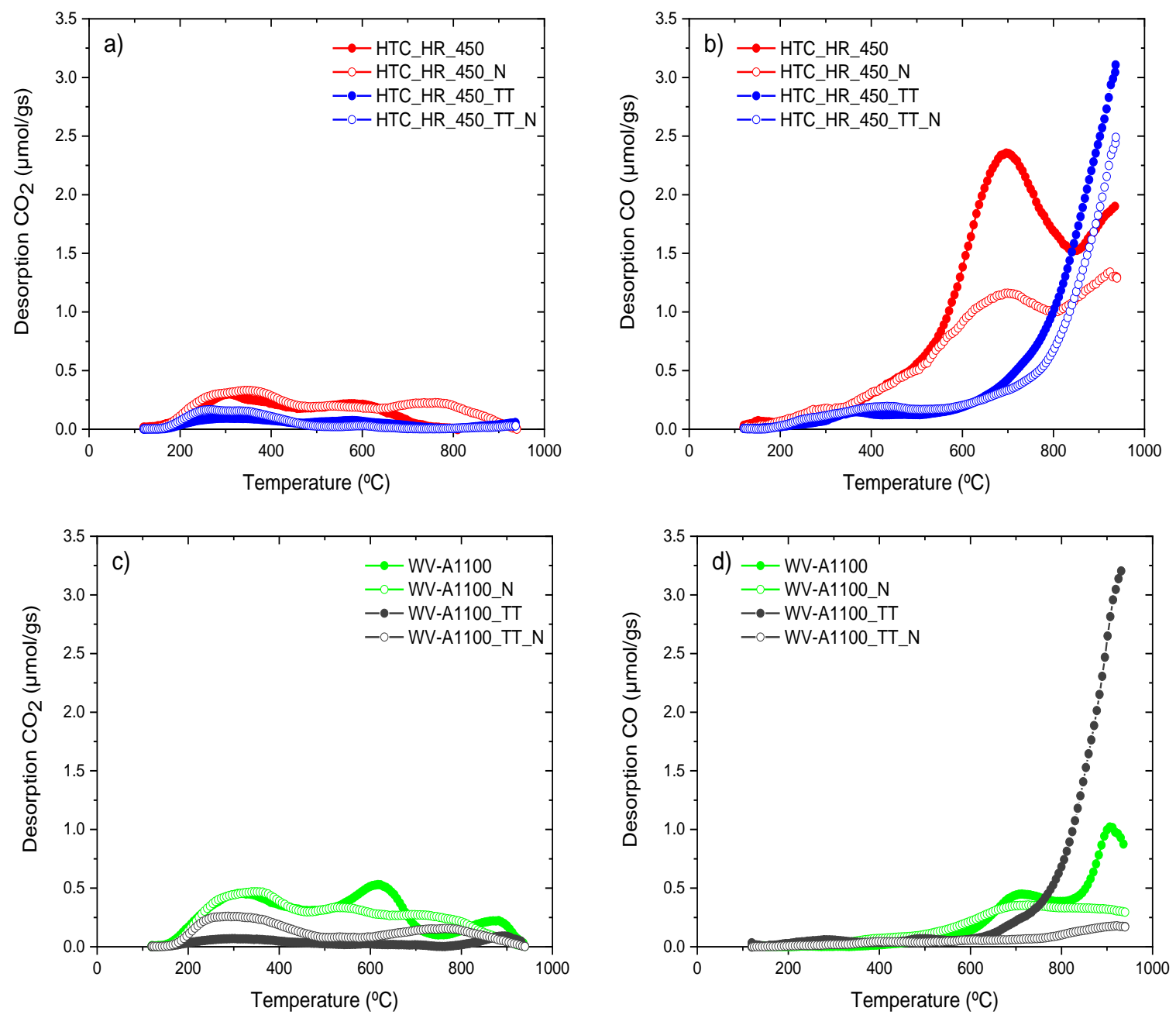

Figure 3. TPD profiles for all activated carbons (a, c) $\mathrm{CO}_{2}$-evolving groups and (b, d) CO-evolving groups. 
The profiles corresponding to the heat-treated activated carbons (samples HTC_HR_450_TT and WV-A1100_TT) show, as expected, an important decrease in the amount of functional groups. As explained previously, the nitrogen functionalization (samples HTC_HR_450_TT_N, and WVA1100_TT_N) produces a decrease in the CO-evolving groups, showing that the substitution reactions occur mainly through carbonyl groups. However, reaction with P-O species forming P$\mathrm{N}$ functionalities cannot be discarded. Interestingly, the surface chemistry of WV-A1100_TT_N in terms of $\mathrm{CO}$ and $\mathrm{CO}_{2}$ type groups is very similar to that of commercial YP-50F sample.

\subsection{Electrochemical characterization}

\subsubsection{Characterization in aqueous electrolyte}

Figure 4 shows the cyclic voltammograms of each activated carbon studied in this work in acid aqueous electrolyte in a potential window between -0.2 and $0.6 \mathrm{~V}$ vs $\mathrm{Ag} / \mathrm{AgCl}$. The voltammograms of HTC_HR_450 and its derivatives show a quasi-rectangular shape (see Figure 4a). It indicates that the double-layer formation is the main contribution to the total capacitance with a value of $141 \mathrm{~F} \mathrm{~g}^{-1}$ for this sample. The voltammogram of HTC_HR_450 also presents a small redox process at around $0.15 \mathrm{~V}$ in the forward scan, which is assigned to the pseudocapacitive contribution of surface oxygen groups [61]. The functionalized activated carbon (HTC_HR_450_N) and those obtained after heat treatment and functionalization (samples HTC_HR_450_TT and HTC_HR_450_TT_N) displayed a decrease in the capacitance compared to sample HTC_HR_450. This is due to changes in porosity and, especially, in surface chemistry. Both, functionalization and heat treatment, remove CO-type groups which can contribute to the pseudocapacitance. As expected, the samples heat treated up to $900{ }^{\circ} \mathrm{C}$ present voltammograms with a more rectangular shape due to increase in the structural order and removal of electronwithdrawing oxygen groups [62-64]. This improvement in electrochemical properties is clearly 
observed with a higher retention of capacitance with increasing scan rate (see Table S1). Interestingly, the highest retention of capacitance is achieved for the heat-treated sample after $\mathrm{N}$ functionalization, demonstrating the positive effect of $\mathrm{N}$ doping in the electrical conductivity of carbon materials [41]. In the case of sample WV-A1100, the functionalized and heat-treated materials, the results obtained are similar to those explained before.
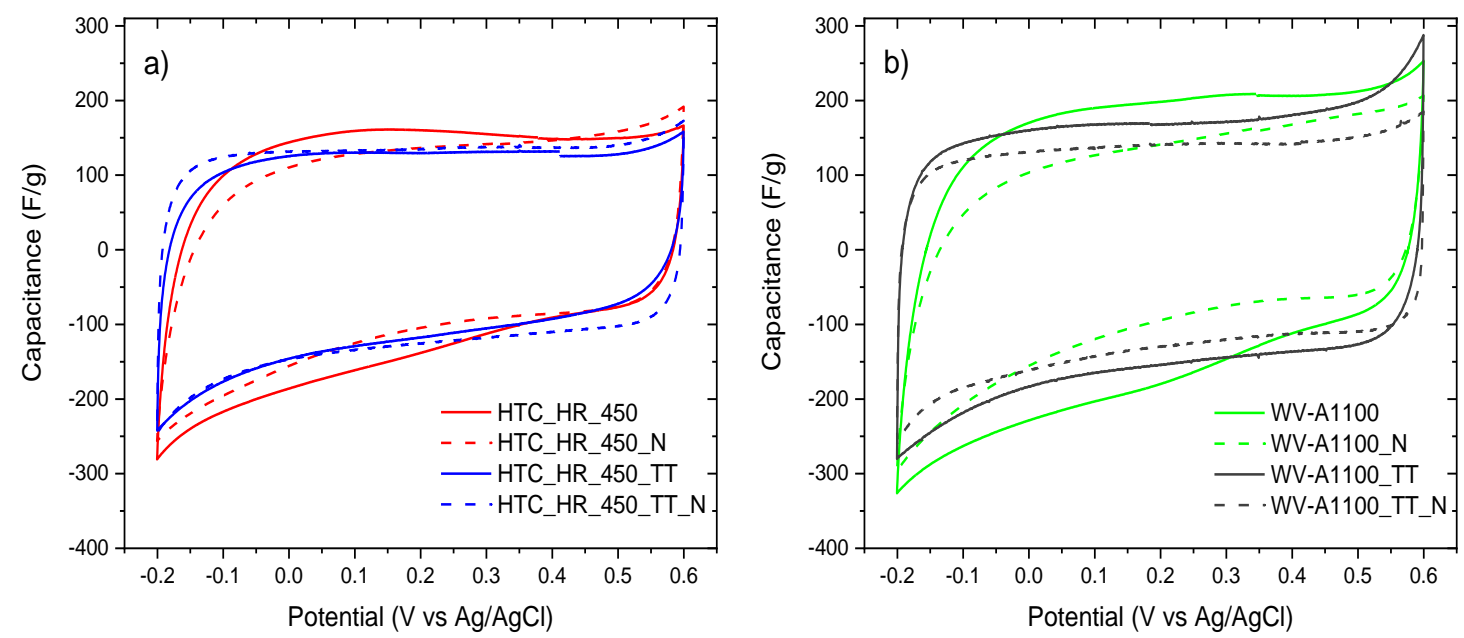

Figure 4. Steady cyclic voltammograms in $1 \mathrm{M} \mathrm{H}_{2} \mathrm{SO}_{4}$ solution of (a) HTC_HR_450 (AC prepared by $\mathrm{H}_{3} \mathrm{PO}_{4}$-assisted HTC) and its counterparts. (b) WV-A1100 (commercial AC) and its modified counterparts. Scan rate: $1 \mathrm{mV} \mathrm{s}^{-1}$.

The materials have also been characterized in wider potential windows. Cyclic voltammograms of all activated carbons did not show substantial differences at upper and lower potential limits when comparing samples prepared at low temperatures and after heat treatment at $900{ }^{\circ} \mathrm{C}$. After heat treatment at high temperatures, the (HTC_HR_450_TT) exhibit a better electrochemical performance (see Table S1). Furthermore, it can be observed that pseudocapacitive processes associated to the presence of oxygen groups almost disappear after combination of both the heattreatment and the nitrogen. 

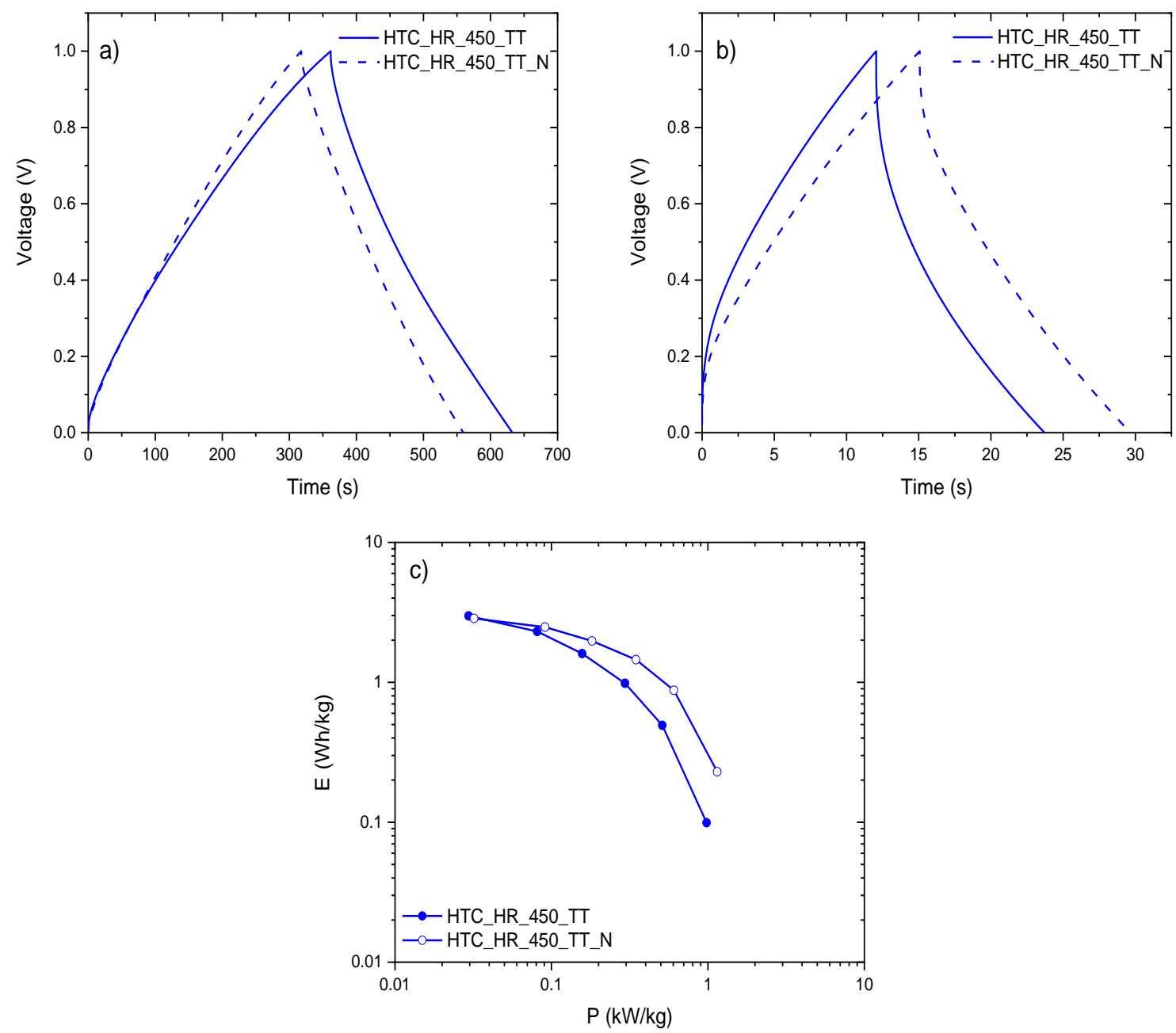

Figure 5. Galvanostatic charge-discharge curves for the symmetric capacitors based on HTC_HR_450_TT and HTC_HR_450_TT_N at different current densities: (a) $0.1 \mathrm{~A} \mathrm{~g}^{-1}$ and (b) 1 $\mathrm{A} \mathrm{g}^{-1}$. (c) Ragone plot at $1.0 \mathrm{~V}$ for both symmetric capacitors. Electrolyte: $1 \mathrm{M} \mathrm{H}_{2} \mathrm{SO}_{4}$ solution.

To determine the behavior of the activated carbons as supercapacitor electrodes, they were characterized in a symmetric two-electrode cell configuration by chronopotentiometry at different current densities in aqueous electrolyte $\left(1 \mathrm{M} \mathrm{H}_{2} \mathrm{SO}_{4}\right)$. Symmetric capacitors based on the heattreated activated carbons (HTC_HR_450_TT and WV-A1100_TT) and their functionalized counterparts displayed better performance than their respective original activated carbons. In fact, the results for the original activated carbons are not included because the performance is not adequate. 
Figures $5 \mathrm{a}$ and $5 \mathrm{~b}$ show the galvanostatic charge-discharge curves of symmetric capacitors based on HTC_HR_450_TT and HTC_HR_450_TT_N at different current densities. It should be noted that HTC_HR_450_TT based capacitor exhibited slightly higher capacitance than the capacitor based on HTC_HR_450_TT_N, in agreement with the higher surface area of this material. Additionally, it can be seen that charge-discharge profile of HTC_HR_450_TT_N-based symmetric capacitor exhibited a triangular shape at $0.1 \mathrm{~A} \mathrm{~g}^{-1}$, while HTC_HR_450_TT-based symmetric capacitor presented a slight deviation, resulting in a lower reversibility during the cycling process that can be associated with a lower occurrence of faradaic reactions. At high current density, HTC_HR_450_TT_N based capacitor displays a lower ohmic drop due to the decrease of resistance caused by the $\mathrm{N}$ doping treatment (see Figure 5b). This result supports the beneficial effect of $\mathrm{N}$-doping since it may increase the electrical conductivity of the material and improve the wettability [41]. Symmetric capacitors based on WV-A1100_TT and WVA1100_TT_N displayed the same electrochemical behavior (see Figure S1).

Figure 5c shows the Ragone plot for HTC_HR based samples. It demonstrates that HTC_HR_450_TT_N-based symmetric capacitor provides higher energy density than capacitor based on HTC_HR_450_TT at high power conditions. In addition, the energy efficiencies in both HTC_HR_450_TT_N and WV-A1100_TT_N-based symmetric capacitor increased around $6 \%$ compared to those of capacitors based on HTC_HR_450_TT and WV-A1100_TT (calculated for a current of $0.1 \mathrm{~A} / \mathrm{g})$.

In order to get further insights, durability tests were performed in a continuous galvanostatic charge-discharge experiment at $1 \mathrm{~A} \mathrm{~g}^{-1}$ for 5000 cycles (graph not shown). They revealed that HTC_HR_450_TT_N-based capacitor retained nearly $100 \%$ of the initial capacitance, while the capacitor based on non-functionalized carbon material kept only $81 \%$. The results show that 
capacitors based on functionalized activated carbons provide higher energy density under high power conditions, as well as greater energy efficiency (see Table $\mathrm{S} 2$ for both AC based materials). These results confirmed that both the heat-treatment and the chemical functionalization improved the electrochemical stability of HTC_HR_450_TT_N and WV-A1100_TT_N when used in aqueous electrolyte. This improvement can be associated to the introduction of nitrogen groups

such as pyrroles, pyridones, and pyridines, which increase the electrochemical stability, wettability and electrical conductivity, and the decrease of oxygen groups that can lead to the degradation of carbon material or decrease of electrical conductivity $[39,43,44]$.

\subsubsection{Symmetric capacitor in organic electrolyte}

In order to demonstrate the applicability of the biomass-based carbon material synthesized in this work, as well as to emphasize the beneficial effect of modifying carbon materials with nitrogen groups through organic reactions under mild conditions, the performance of the developed carbon materials-based capacitors in organic electrolyte was evaluated. Figures $6 a$ and $6 \mathrm{~b}$ show the galvanostatic charge-discharge cycles of symmetric capacitors based on HTC_HR_450 and WVA1100 and their modified counterparts, in organic electrolyte at $0.25 \mathrm{~A} \mathrm{~g}^{-1}$ and Table 3 contains a summary of the parameters of the capacitors during the first cycles and it also includes the retention of capacitance after the durability test. The figure and the table also contain the results for a symmetric capacitor built with commercial YP50F activated carbon. 

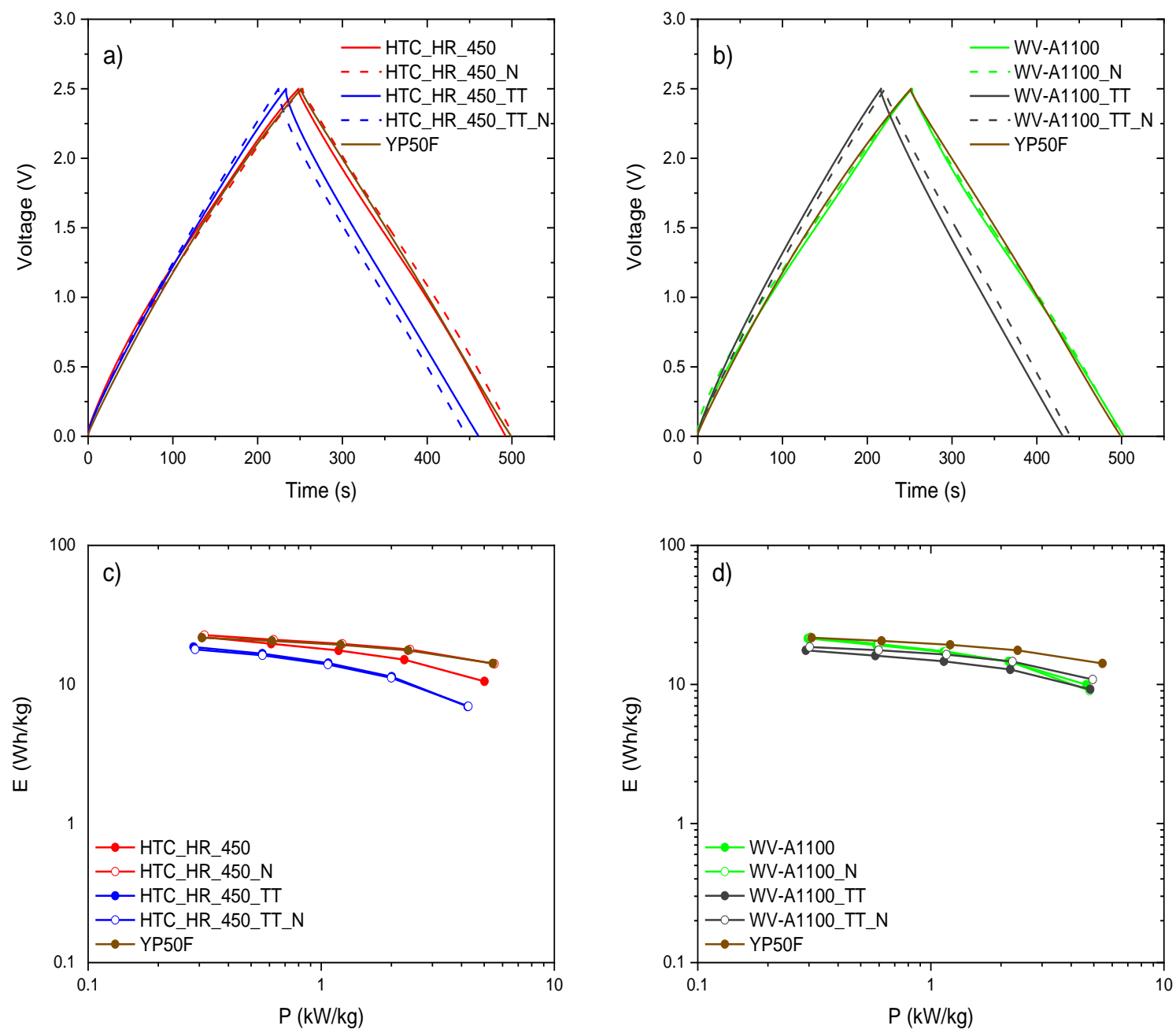

Figure 6. Galvanostatic charge-discharge cycles of the symmetric capacitors of (a) activated hydrothermal carbon (HTC_HR_450) and their modified counterparts and YP50F (b) WV-A1100 (commercial) and their modified counterparts and YP50F $\left(\mathrm{j}=0.25 \mathrm{~A} \mathrm{~g}^{-1}\right)$. Ragone plot of symmetric capacitors at $2.5 \mathrm{~V}(\mathrm{c}, \mathrm{d})$. Electrolyte: $1 \mathrm{M}$ TEMA-BF $4 / \mathrm{PC}$.

It can be observed that all symmetric capacitors, when measured at low currents, exhibited a triangular shape similar to that of capacitor based on YP50F, which is an activated carbon specially used in commercial capacitors in organic electrolyte (Figures 6a and 6b). Furthermore, their performance during the first charge-discharge cycles is very similar to YP50F-based capacitor (Table 3), especially for those materials which have similar porosity and surface area (i.e., HTC_HR-450 and WV-1100). Moreover, it should be mentioned that energy efficiencies for all samples are comparable to that of YP50F-based capacitor (see Table 3). 
Table 3. Power and energy density values of the symmetric capacitors by galvanostatic charge-discharge cycles at $2.5 \mathrm{~V}$. Electrolyte: $1 \mathrm{M}$ TEMA-BF $/ \mathrm{PC}, \mathrm{j}=0.25 \mathrm{~A} \mathrm{~g}^{-1}$.

\begin{tabular}{|c|c|c|c|c|c|c|}
\hline Capacitor & $\begin{array}{c}\mathrm{C} / \\
\mathrm{F} \mathrm{g}^{-1}\end{array}$ & $\begin{array}{c}\text { E / } \\
W_{h} k^{-1}\end{array}$ & 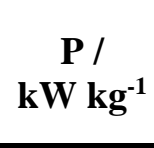 & $\begin{array}{c}\text { Coulombic } \\
\text { Efficiency } \\
(\%)\end{array}$ & $\begin{array}{c}\text { Energy } \\
\text { Efficiency } \\
(\%)\end{array}$ & $\begin{array}{c}\mathbf{C}_{\mathrm{f}} / \mathrm{C}_{\mathrm{f}} \\
(\%)\end{array}$ \\
\hline HTC_HR_450 & 25 & 21.9 & 0.31 & 98 & 87 & 73 \\
\hline HTC_HR_450_N & 25 & 22.6 & 0.32 & 98 & 90 & 68 \\
\hline HTC_HR_450_TT & 23 & 18.6 & 0.28 & 97 & 83 & 79 \\
\hline HTC_HR_450_TT_N & 22 & 17.9 & 0.28 & 99 & 85 & 86 \\
\hline WV-A1100 & 25 & 21.4 & 0.30 & 99 & 86 & 70 \\
\hline WV-A1100_N & 25 & 21.8 & 0.30 & 98 & 86 & 70 \\
\hline WV-A1100_TT & 22 & 17.6 & 0.29 & 99 & 85 & 87 \\
\hline WV-A1100_TT_N & 22 & 18.6 & 0.30 & 99 & 89 & 90 \\
\hline YP50F & 25 & 21.7 & 0.31 & 98 & 89 & 97 \\
\hline
\end{tabular}

Figures $6 \mathrm{c}$ and $6 \mathrm{~d}$ show the Ragone plots of the symmetric capacitors. It can be seen that the activated carbons derived from HTC_HR_450 have a slightly lower performance in terms of energy density at high power demand with respect to the YP50F performance. This may be attributed to the textural properties because the HR-derived activated carbons have narrower PSD than YP50F. Sample HTC_HR_450 presents the worst performance since this material is the one with the lowest structural order and the highest amount of oxygen groups (see Table 1). The effect of $\mathrm{N}$ functionalization is clearly observed when sample HTC_HR_450 is compared with HTC_HR_450_N (Figure 6c). In the case of pristine WV-A1100 sample, the decrease in energy with power is more important and similar to what was observed with HTC_HR_450 sample. For capacitors based on WV-A1100-derived ACs (Figure 6d) when specific current increased (high power demand), the energy density did not decay significantly compared to HTC_HR_450-derived ACs, indicating the beneficial effect of mesoporosity of WV-A1100-derived ACs when using organic electrolytes. It must be noted that the performance of these materials is close to the commercial AC in spite of their lower porosity (especially for the heat treated materials), demonstrating the positive role of a wide pore size distribution with some mesoporosity 
contribution in the case of organic electrolytes. YP-50F has an essentially microporous character without significant mesoporosity contribution.

Durability tests were also performed by galvanostatic charge-discharge experiments at $1 \mathrm{~A} \mathrm{~g}^{-1}$ for 5000 cycles (see Figure S2 and Table S3). Table 3 shows the values of retention of capacitance after durability test and Figure 7 contains the charge-discharge experiments and the Ragone plots after durability test. The results show that the heat treated materials after functionalization with $\mathrm{N}$ have higher retention of capacitance (Table 3). The effect of both heat treatment and $\mathrm{N}$ functionalization, which increase the structural order and decrease reactivity of the materials (due to the changes in surface chemistry), explain the good performance of these activated carbons, becoming comparable compared to the commercial AC. Among them, the commercial activated carbon WV-A1100 after heat treatment and functionalization produces the best results in terms of energy, power and durability, with a performance very close to the YP50F material (Table 3 and Figure 7). In this case, not only the above mentioned properties explain the remarkable performance, but also the mesoporosity contribution that, in organic electrolyte, is a positive factor to achieve a good rate performance. 

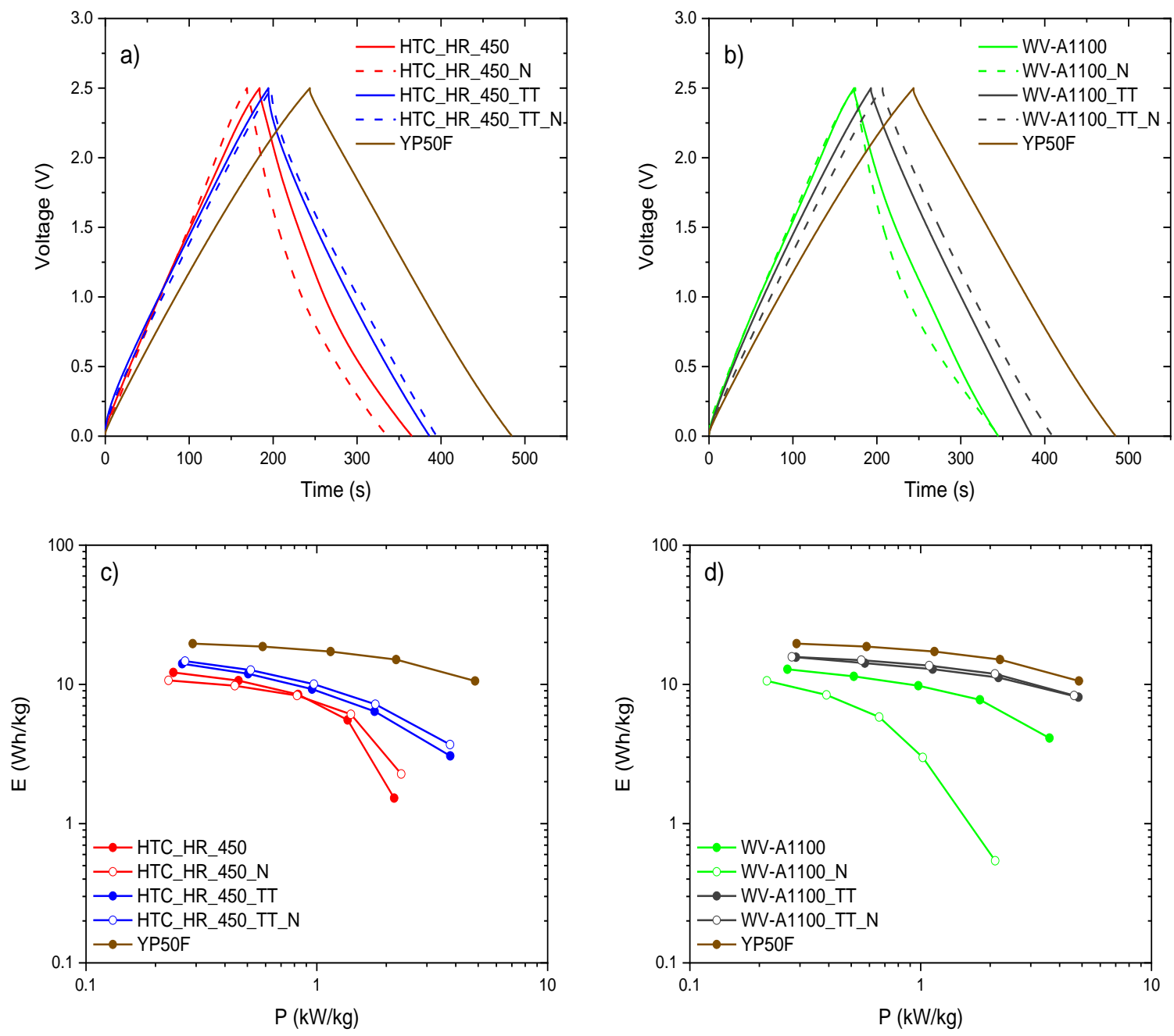

Figure 7. Galvanostatic charge-discharge cycles of the symmetric capacitors after durability test of (a) activated hydrothermal carbon (HTC_HR_450) and their modified counterparts and YP50F (b) WV-A1100 (commercial) and their modified counterparts and YP50F $\left(\mathrm{j}=0.25 \mathrm{~A} \mathrm{~g}^{-1}\right)$. Ragone plot of symmetric capacitors at $2.5 \mathrm{~V}$ after durability test (c, d). Electrolyte: $1 \mathrm{M}$ TEMA-BF $/ \mathrm{PC}$.

\section{Conclusion}

The results show that from low cost $\mathrm{AC}$ prepared by $\mathrm{H}_{3} \mathrm{PO}_{4}$ and after application of straightforward methods like heat treatment in inert atmosphere and $\mathrm{N}$-doping at mild conditions, $\mathrm{AC}$ for supercapacitors with comparable properties to the commercial AC, can be obtained. The heat treatment permits an increase in the structural order and the removal of oxygen functional groups that increase electrical conductivity and electrochemical stability. The $\mathrm{N}$-doping allows us to refine the chemical and electrochemical properties since it improves electrical conductivity and 
electrochemical stability. This approach results in higher yields of activated carbon compared to conventional carbonization followed by physical activation with steam (above $30 \mathrm{wt} \%$ for a conventional $\mathrm{H}_{3} \mathrm{PO}_{4}$ activation versus less than $10 \mathrm{wt} \%$ for physical activation, both calculated with respect to the mass of precursor) and the application of low cost treatments (compared to detailed purification and heat treatments applied for commercial AC for SC). The porous texture and surface chemistry obtained through this methodology can be close to the commercial AC.

Another important aspect developed in this study that can be of interest from an application point of view is the use of phosphoric acid assisted HTC for AC preparation from biomass residues. This methodology permits the preparation of $\mathrm{AC}$ using lower concentrations of $\mathrm{H}_{3} \mathrm{PO}_{4}$ obtaining higher yields and higher porosity development. This is not only relevant from an economic point of view, but also an effective way of approaching a more environmentally friendly protocol. Due to the experimental conditions of the $\mathrm{H}_{3} \mathrm{PO}_{4}$-assited $\mathrm{HTC}$, that is low $\mathrm{H}_{3} \mathrm{PO}_{4}$ concentration (25 wt $\%$ versus higher than $50 \%$ in the conventional preparation method), the re-use of the activating agent in subsequent activation steps is easier and less energy demanding to achieve the necessary concentration.

For all these reasons the materials developed in this study could pave the way for the preparation of green and cost-effective activated carbon materials from biomass residues for SC. It could be expected that the protocol herein applied could be used for the preparation of high-performance carbon materials for energy and environmental applications, which could be competitive in the marketplace.

E-supplementary data of this work can be found in online version of the paper. 


\section{Acknowledgements}

This research was partially supported by the MICINN, FEDER (RTI2018-095291-B-I00). JCG thanks for her predoctoral scholarship (GRISOLIA / 2018/105) funded by the Generalitat Valenciana and DST thanks MICINN for the "Juan de la Cierva" contract (IJCI-2016-27636).

\section{References}

[1] M.K. Islam, H. Wang, S. Rehman, C. Dong, H.Y. Hsu, C.S.K. Lin, S.Y. Leu, Sustainability metrics of pretreatment processes in a waste derived lignocellulosic biomass biorefinery, Bioresour. Technol. 298 (2020) 122558. https://doi.org/10.1016/j.biortech.2019.122558.

[2] P. Sudarsanam, E. Peeters, E. V. Makshina, V.I. Parvulescu, B.F. Sels, Advances in porous and nanoscale catalysts for viable biomass conversion, Chem. Soc. Rev. 48 (2019) 23662421. https://doi.org/10.1039/c8cs00452h.

[3] F. Cherubini, The biorefinery concept: Using biomass instead of oil for producing energy and chemicals, Energy Convers. Manag. $51 \quad$ (2010) 1412-1421. https://doi.org/10.1016/j.enconman.2010.01.015.

[4] B. Kamm, M. Kamm, P. R. Gruber and S. Kromus, in Biorefineries-Industrial Processes and Products, eds. B. Kamm, P. R. Gruber, M. Kamm, Wiley-VCH, Weinheim, 2005, Biorefinery Systems - An Overview (Chapter 1), pp. 1-40.. https://doi.org/10.1002/9783527619849.ch1.

[5] S. Dahiya, A.N. Kumar, J. Shanthi Sravan, S. Chatterjee, O. Sarkar, S. V Mohan, Food waste biorefinery: Sustainable strategy for circular bioeconomy, Bioresour. Technol. 248 (2018) 2-12. https://doi.org/10.1016/j.biortech.2017.07.176.

[6] W. Schutyser, T. Renders, S. den Bosch, S.-F. Koelewijn, G.T. Beckham, B.F. Sels, Chemicals from lignin: an interplay of lignocellulose fractionation, depolymerisation, and upgrading, Chem. Soc. Rev. 47 (2018) 852-908. https://doi.org/10.1039/C7CS00566K.

[7] F.D. Pileidis, M.-M. Titirici, Levulinic Acid Biorefineries: New Challenges for Efficient Utilization of Biomass, ChemSusChem. 9 (2016) 562-582. https://doi.org/10.1002/cssc.201501405. 
[8] E.J. Cho, L.T.P. Trinh, Y. Song, Y.G. Lee, H.J. Bae, Bioconversion of biomass waste into high value chemicals, Bioresour. Technol. $298 \quad$ (2020) 122386. https://doi.org/10.1016/j.biortech.2019.122386.

[9] W. Dessie, X. Luo, M. Wang, L. Feng, Y. Liao, Z. Wang, Z. Yong, Z. Qin, Current advances on waste biomass transformation into value-added products, Appl. Microbiol. Biotechnol. 104 (2020) 4757-4770. https://doi.org/10.1007/s00253-020-10567-2.

[10] J.S. Luterbacher, D. Martin Alonso, J.A. Dumesic, Targeted chemical upgrading of lignocellulosic biomass to platform molecules, Green Chem. 16 (2014) 4816-4838. https://doi.org/10.1039/C4GC01160K.

[11] R. Rinaldi, R. Jastrzebski, M.T. Clough, J. Ralph, M. Kennema, P.C.A. Bruijnincx, B.M. Weckhuysen, Paving the Way for Lignin Valorisation: Recent Advances in Bioengineering, Biorefining and Catalysis, Angew. Chemie Int. Ed. 55 (2016) 8164-8215. https://doi.org/10.1002/anie.201510351.

[12] M.J. Climent, A. Corma, S. Iborra, Conversion of biomass platform molecules into fuel additives and liquid hydrocarbon fuels, Green Chem. 16 (2014) 516-547. https://doi.org/10.1039/C3GC41492B.

[13] W.-J. Liu, H. Jiang, H.-Q. Yu, Development of Biochar-Based Functional Materials: Toward a Sustainable Platform Carbon Material, Chem. Rev. 115 (2015) 12251-12285. https://doi.org/10.1021/acs.chemrev.5b00195.

[14] J. Deng, M. Li, Y. Wang, Biomass-derived carbon: synthesis and applications in energy storage and conversion, Green Chem. $18 \quad$ (2016) 4824-4854. https://doi.org/10.1039/C6GC01172A.

[15] X.-F. Tan, S.-B. Liu, Y.-G. Liu, Y.-L. Gu, G.-M. Zeng, X.-J. Hu, X. Wang, S.-H. Liu, L.H. Jiang, Biochar as potential sustainable precursors for activated carbon production: Multiple applications in environmental protection and energy storage, Bioresour. Technol. 227 (2017) 359-372. https://doi.org/10.1016/j.biortech.2016.12.083.

[16] H. Durak, Y. Genel, Hydrothermal conversion of biomass (Xanthium strumarium) to energetic materials and comparison with other thermochemical methods, J. Supercrit. 
Fluids. 140 (2018) 290-301. https://doi.org/10.1016/j.supflu.2018.07.005.

[17] M.M. Titirici, M. Antonietti, Chemistry and materials options of sustainable carbon materials made by hydrothermal carbonization, Chem. Soc. Rev. 39 (2010) 103-116. https://doi.org/10.1039/b819318p.

[18] F. Quesada-Plata, R. Ruiz-Rosas, E. Morallón, D. Cazorla-Amorós, Activated Carbons Prepared through H3PO4-Assisted Hydrothermal Carbonisation from Biomass Wastes: Porous Texture and Electrochemical Performance, Chempluschem. 81 (2016) 1349-1359. https://doi.org/10.1002/cplu.201600412.

[19] S. Carrasco, J. Silva, E. Pino-Cortés, J. Gómez, F. Vallejo, L. Díaz-Robles, V. Campos, F. Cubillos, S. Pelz, S. Paczkowski, F. Cereceda-Balic, A. Vergara-Fernández, M. Lapuerta, A. Pazo, E. Monedero, K. Hoekman, Experimental study on hydrothermal carbonization of lignocellulosic biomass with magnesium chloride for solid fuel production, Processes. 8 (2020) 1-12. https://doi.org/10.3390/PR8040444.

[20] R. Sharma, K. Jasrotia, N. Singh, P. Ghosh, S. srivastava, N.R. Sharma, J. Singh, R. Kanwar, A. Kumar, A Comprehensive Review on Hydrothermal Carbonization of Biomass and its Applications, Chem. Africa. 3 (2020) 1-19. https://doi.org/10.1007/s42250-01900098-3.

[21] J.M. Rosas, R. Berenguer, M.J. Valero-Romero, J. Rodríguez-Mirasol, T. Cordero, Preparation of different carbon materials by thermochemical conversion of lignin, Front. Mater. 1 (2014) 1-17. https://doi.org/10.3389/fmats.2014.00029.

[22] K. MacDermid-Watts, R. Pradhan, A. Dutta, Catalytic Hydrothermal Carbonization Treatment of Biomass for Enhanced Activated Carbon: A Review, Waste and Biomass Valorization. (2020). https://doi.org/10.1007/s12649-020-01134-x.

[23] L. Wei, M. Sevilla, A.B. Fuertes, R. Mokaya, G. Yushin, Hydrothermal carbonization of abundant renewable natural organic chemicals for high-performance supercapacitor electrodes, Adv. Energy Mater. 1 (2011) 356-361. https://doi.org/10.1002/aenm.201100019.

[24] C. Falco, J.P. Marco-Lozar, D. Salinas-Torres, E. Morallón, D. Cazorla-Amorós, M.M. 
Titirici, D. Lozano-Castelló, Tailoring the porosity of chemically activated hydrothermal carbons: Influence of the precursor and hydrothermal carbonization temperature, Carbon. 62 (2013) 346-355. https://doi.org/10.1016/j.carbon.2013.06.017.

[25] J. Li, B. Michalkiewicz, J. Min, C. Ma, X. Chen, J. Gong, E. Mijowska, T. Tang, Selective preparation of biomass-derived porous carbon with controllable pore sizes toward highly efficient CO2 capture, Chem. Eng. J. $360 \quad$ (2019) 250-259. https://doi.org/10.1016/j.cej.2018.11.204.

[26] H. Yang, S. Ye, J. Zhou, T. Liang, Biomass-derived porous carbon materials for supercapacitor, Front. Chem. 7 (2019) 1-17. https://doi.org/10.3389/fchem.2019.00274.

[27] G.P. Awasthi, D.P. Bhattarai, B. Maharjan, K.S. Kim, C.H. Park, C.S. Kim, Synthesis and characterizations of activated carbon from Wisteria sinensis seeds biomass for energy storage applications, J. Ind. Eng. Chem. 72 (2019) 265-272. https://doi.org/10.1016/j.jiec.2018.12.027.

[28] A.G. Pandolfo, A.F. Hollenkamp, Carbon properties and their role in supercapacitors, J. Power Sources. 157 (2006) 11-27. https://doi.org/10.1016/j.jpowsour.2006.02.065.

[29] E. Raymundo-Piñero, K. Kierzek, J. Machnikowski, F. Béguin, Relationship between the nanoporous texture of activated carbons and their capacitance properties in different electrolytes, Carbon. 44 (2006) 2498-2507. https://doi.org/10.1016/j.carbon.2006.05.022.

[30] K. Xia, Q. Gao, J. Jiang, J. Hu, Hierarchical porous carbons with controlled micropores and mesopores for supercapacitor electrode materials, Carbon. 46 (2008) 1718-1726. https://doi.org/10.1016/j.carbon.2008.07.018.

[31] C. Vix-Guterl, E. Frackowiak, K. Jurewicz, M. Friebe, J. Parmentier, F. Béguin, Electrochemical energy storage in ordered porous carbon materials, Carbon. 43 (2005) 1293-1302. https://doi.org/10.1016/j.carbon.2004.12.028.

[32] O. Oginni, K. Singh, G. Oporto, B. Dawson-Andoh, L. McDonald, E. Sabolsky, Effect of one-step and two-step $\mathrm{H}_{3} \mathrm{PO}_{4}$ activation on activated carbon characteristics, Bioresour. Technol. Reports. 8 (2019) 100307. https://doi.org/10.1016/j.biteb.2019.100307.

[33] A.H. Jawad, N.N. Mohd Firdaus Hum, A.S. Abdulhameed, M.A. Mohd Ishak, Mesoporous 
activated carbon from grass waste via H3PO4-activation for methylene blue dye removal: modelling, optimisation, and mechanism study, Int. J. Environ. Anal. Chem. 00 (2020) 117. https://doi.org/10.1080/03067319.2020.1807529.

[34] C. Srinivasakannan, Z.M. Abu Bakar, Production of activated carbon from rubber wood sawdust, Biomass and Bioenergy. 27 (2004) 89-96. https://doi.org/10.1016/j.biombioe.2003.11.002.

[35] M. Jagtoyen, F. Derbyshire, Activated carbons from yellow poplar and white oak by $\mathrm{H}_{3} \mathrm{PO}_{4}$ activation, Carbon. 36 (1998) 1085-1097. https://doi.org/10.1016/S0008-6223(98)000827.

[36] Y. Wu, J.P. Cao, X.Y. Zhao, Q.Q. Zhuang, Z. Zhou, M. Zhao, X. Cui, Y.P. Zhao, X.Y. Wei, Sustainable Porous Carbon with High Specific Surface Area from Soybean Shell via Hydrothermal Carbonization with $\mathrm{H}_{3} \mathrm{PO}_{4}$ for Electric Double-Layer Capacitor Applications, Energy Technol. 8 (2020) 1-9. https://doi.org/10.1002/ente.201901103.

[37] Y. Shi, G. Liu, L. Wang, H. Zhang, Activated carbons derived from hydrothermal impregnation of sucrose with phosphoric acid: Remarkable adsorbents for sulfamethoxazole removal, RSC Adv. 9 (2019) 17841-17851. https://doi.org/10.1039/c9ra02610j.

[38] A.J. Romero-Anaya, M.A. Lillo-Ródenas, C. Salinas-Martínez De Lecea, A. LinaresSolano, Hydrothermal and conventional $\mathrm{H}_{3} \mathrm{PO}_{4}$ activation of two natural bio-fibers, Carbon. 50 (2012) 3158-3169. https://doi.org/10.1016/j.carbon.2011.10.031.

[39] D. Salinas-Torres, S. Shiraishi, E. Morallón, D. Cazorla-Amorós, Improvement of carbon materials performance by nitrogen functional groups in electrochemical capacitors in organic electrolyte at severe conditions, Carbon. 82 (2015) 205-213. https://doi.org/10.1016/j.carbon.2014.10.064.

[40] D. Cazorla-Amorós, D. Lozano-Castelló, E. Morallón, M.J. Bleda-Martínez, A. LinaresSolano, S. Shiraishi, Measuring cycle efficiency and capacitance of chemically activated carbons in propylene carbonate, Carbon. 48 (2010) 1451-1456. https://doi.org/10.1016/j.carbon.2009.12.039. 
[41] M.J. Mostazo-López, R. Ruiz-Rosas, A. Castro-Muñiz, H. Nishihara, T. Kyotani, E. Morallón, D. Cazorla-Amorós, Ultraporous nitrogen-doped zeolite-templated carbon for high power density aqueous-based supercapacitors, Carbon. 129 (2018) 510-519. https://doi.org/10.1016/j.carbon.2017.12.050.

[42] D. Salinas-Torres, R. Ruiz-Rosas, E. Morallon, D. Cazorla-Amoros, Strategies to enhance the performance of electrochemical capacitors based on carbon materials, Front. Mater. 6 (2019) 115. https://doi.org/10.3389/FMATS.2019.00115.

[43] M.J. Mostazo-López, R. Ruiz-Rosas, E. Morallón, D. Cazorla-Amorós, Generation of nitrogen functionalities on activated carbons by amidation reactions and Hofmann rearrangement: Chemical and electrochemical characterization, Carbon. 91 (2015) 252265. https://doi.org/10.1016/j.carbon.2015.04.089.

[44] M.J. Mostazo-López, R. Ruiz-Rosas, E. Morallón, D. Cazorla-Amorós, Nitrogen doped superporous carbon prepared by a mild method. Enhancement of supercapacitor performance, Int. J. Hydrogen Energy. 41 (2016) 19691-19701. https://doi.org/10.1016/j.ijhydene.2016.03.091.

[45] T. Tagaya, Y. Hatakeyama, S. Shiraishi, H. Tsukada, M.J. Mostazo-López, E. Morallón, D. Cazorla-Amorós, Nitrogen-Doped Seamless Activated Carbon Electrode with Excellent Durability for Electric Double Layer Capacitor, J. Electrochem. Soc. 167 (2020) 060523. https://doi.org/10.1149/1945-7111/ab8403.

[46] W. Shen, W. Fan, Nitrogen-containing porous carbons: synthesis and application, J. Mater. Chem. A. 1 (2013) 999-1013. https://doi.org/10.1039/C2TA00028H.

[47] D. Salinas-Torres, M. Navlani-García, K. Mori, Y. Kuwahara, H. Yamashita, Nitrogendoped carbon materials as a promising platform toward the efficient catalysis for hydrogen generation, Appl. Catal. A Gen. $571 \quad$ (2019) 25-41. https://doi.org/10.1016/J.APCATA.2018.11.034.

[48] S. Shiraishi, Heat-Treatment and Nitrogen-Doping of Activated Carbons for High Voltage Operation of Electric Double Layer Capacitor, Key Eng. Mater. 497 (2011) 80-86. https://doi.org/10.4028/www.scientific.net/KEM.497.80. 
[49] M. Thommes, K. Kaneko, A. V. Neimark, J.P. Olivier, F. Rodriguez-Reinoso, J. Rouquerol, K.S.W. Sing, Physisorption of gases, with special reference to the evaluation of surface area and pore size distribution (IUPAC Technical Report), Pure Appl. Chem. (2015). https://doi.org/10.1515/pac-2014-1117.

[50] J. Jagiello, J.P. Olivier, 2D-NLDFT adsorption models for carbon slit-shaped pores with surface energetical heterogeneity and geometrical corrugation, Carbon. 55 (2013) 70-80. https://doi.org/10.1016/j.carbon.2012.12.011.

[51] M.J. Muñoz-Guillena, A. Linares-Solano, C.S.M. de Lecea, Determination of calorific values of coals by differential thermal analysis, Fuel. 71 (1992) 579-583. https://doi.org/10.1016/0016-2361(92)90157-J.

[52] I. Martin-Gullon, J.P. Marco-Lozar, D. Cazorla-Amorós, A. Linares-Solano, Analysis of the microporosity shrinkage upon thermal post-treatment of $\mathrm{H}_{3} \mathrm{PO}_{4}$ activated carbons, Carbon. 42 (2004) 1339-1343. https://doi.org/10.1016/j.carbon.2004.01.018.

[53] Y. Yamada, J. Kim, S. Matsuo, S. Sato, Nitrogen-containing graphene analyzed by X-ray photoelectron $\quad$ spectroscopy, $\quad$ Carbon. $\quad 70 \quad$ 59-74. https://doi.org/10.1016/j.carbon.2013.12.061.

[54] E. Raymundo-Piñero, D. Cazorla-Amorós, A. Linares-Solano, J. Find, U. Wild, R. Schlögl, Structural characterization of N-containing activated carbon fibers prepared from a low softening point petroleum pitch and a melamine resin, Carbon. 40 (2002) 597-608. https://doi.org/10.1016/S0008-6223(01)00155-5.

[55] E. Raymundo-Piñero, D. Cazorla-Amorós, A. Linares-Solano, The role of different nitrogen functional groups on the removal of $\mathrm{SO}_{2}$ from flue gases by $\mathrm{N}$-doped activated carbon powders and fibres, Carbon. 41 (2003) 1925-1932. https://doi.org/10.1016/S00086223(03)00180-5.

[56] F. Kapteijn, J.A. Moulijn, S. Matzner, H.P. Boehm, Development of nitrogen functionality in model chars during gasification in CO2 and O2, Carbon. 37 (1999) 1143-1150. https://doi.org/10.1016/S0008-6223(98)00312-1.

[57] R.J.J. Jansen, H. van Bekkum, XPS of nitrogen-containing functional groups on activated 
carbon, Carbon. 33 (1995) 1021-1027. https://doi.org/10.1016/0008-6223(95)00030-H.

[58] M. V Lopez-Ramon, F. Stoeckli, C. Moreno-Castilla, F. Carrasco-Marin, On the characterization of acidic and basic surface sites on carbons by various techniques, Carbon. 37 (1999) 1215-1221. https://doi.org/10.1016/S0008-6223(98)00317-0.

[59] M.C. Román-Martínez, D. Cazorla-Amorós, A. Linares-Solano, C.S.-M. de Lecea, TPD and TPR characterization of carbonaceous supports and Pt/C catalysts, Carbon. 31 (1993) 895-902. https://doi.org/10.1016/0008-6223(93)90190-L.

[60] J.L. Figueiredo, M.F.R. Pereira, M.M.A. Freitas, J.J.M. Órfão, Modification of the surface chemistry of activated carbons, Carbon. 37 (1999) 1379-1389. https://doi.org/10.1016/S0008-6223(98)00333-9.

[61] M.J. Bleda-Martínez, D. Lozano-Castelló, E. Morallón, D. Cazorla-Amorós, A. LinaresSolano, Chemical and electrochemical characterization of porous carbon materials, Carbon. 44 (2006) 2642-2651. https://doi.org/10.1016/j.carbon.2006.04.017.

[62] L. Zhao, N. Baccile, S. Gross, Y. Zhang, W. Wei, Y. Sun, M. Antonietti, M.-M. Titirici, Sustainable nitrogen-doped carbonaceous materials from biomass derivatives, Carbon. 48 (2010) 3778-3787. https://doi.org/10.1016/j.carbon.2010.06.040.

[63] M.J. Bleda-Martínez, J.A. Maciá-Agulló, D. Lozano-Castelló, E. Morallón, D. CazorlaAmorós, A. Linares-Solano, Role of surface chemistry on electric double layer capacitance of carbon materials, Carbon. 43 (2005) 2677-2684. https://doi.org/10.1016/j.carbon.2005.05.027.

[64] H. Marsh and F. Rodríguez-Reinoso, in Activated Carbon, eds. H. Marsh and F. RodríguezReinoso, Elsevier Science Ltd, Oxford, 2006, Activation Processes (Chapter 5), pp. 243321. https://doi.org/10.1016/B978-008044463-5/50019-4. 


\section{Supplementary Data}

\section{Biomass waste conversion into low-cost carbon-based materials for supercapacitors: A sustainable approach for the energy scenario.}

Jessica Chaparro-Garnica a, David Salinas-Torres ${ }^{b}$, Maria José Mostazo-López ${ }^{a}$, Emilia Morallón $^{b}$, Diego Cazorla-Amorós ${ }^{\mathrm{a}, *}$

${ }^{a}$ Departamento de Química Inorgánica and Instituto Universitario de Materiales, Universidad de Alicante, Apartado 99, 03080-Alicante, España

b Departamento de Química Física and Instituto Universitario de Materiales, Universidad de Alicante, Apartado 99, 03080-Alicante, España

*Corresponding Authors: cazorla@ua.es. Diego Cazorla-Amorós, Departamento de Química Inorgánica e Instituto Universitario de Materiales, University of Alicante, P.O. Box 99, San Vicente del Raspeig, E-03080, Alicante, Spain. Phone number: +34965903946. 
Table S1. Capacitance at different scan rates and retention of capacitance of all samples

\begin{tabular}{|c|c|c|c|}
\hline Sample & $\mathrm{C} / \mathrm{F} \mathrm{g} \mathrm{g}^{-1}$ at $1 \mathrm{mV} \mathrm{s}^{-1}$ & $\mathrm{C} / \mathrm{F} \mathrm{g}^{-1}$ at $50 \mathrm{mV} \mathrm{s}^{-1}$ & $\mathrm{C}_{\text {retention }}(\%)$ \\
\hline HTC_HR_450 & 141 & 35 & 25 \\
\hline HTC_HR_450_N & 124 & 19 & 15 \\
\hline HTC_HR_450_TT & 121 & 54 & 45 \\
\hline HTC_HR_450_TT_N & 132 & 84 & 64 \\
\hline WV-A1100 & 173 & 42 & 24 \\
\hline WV-A1100_N & 127 & 14 & 11 \\
\hline WV-A1100_TT & 162 & 109 & 67 \\
\hline WV-A1100_TT_N & 138 & 99 & 72 \\
\hline
\end{tabular}
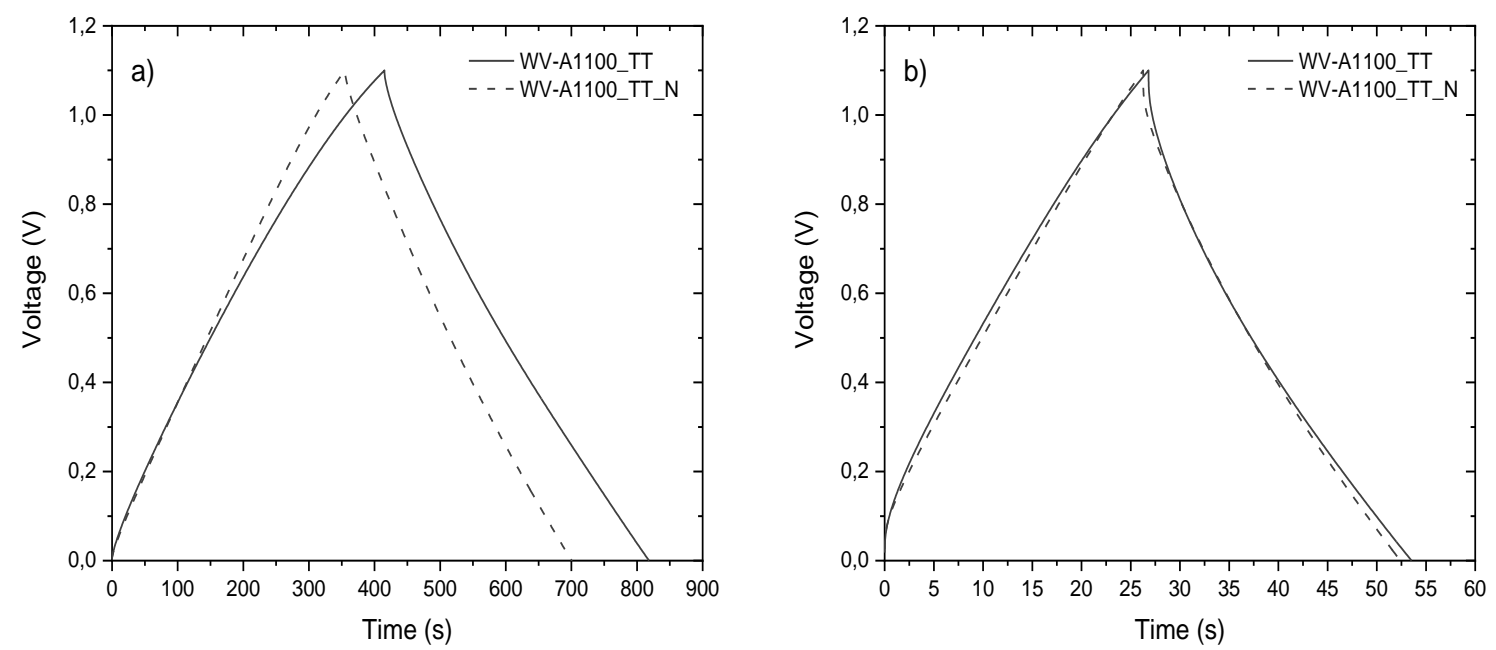


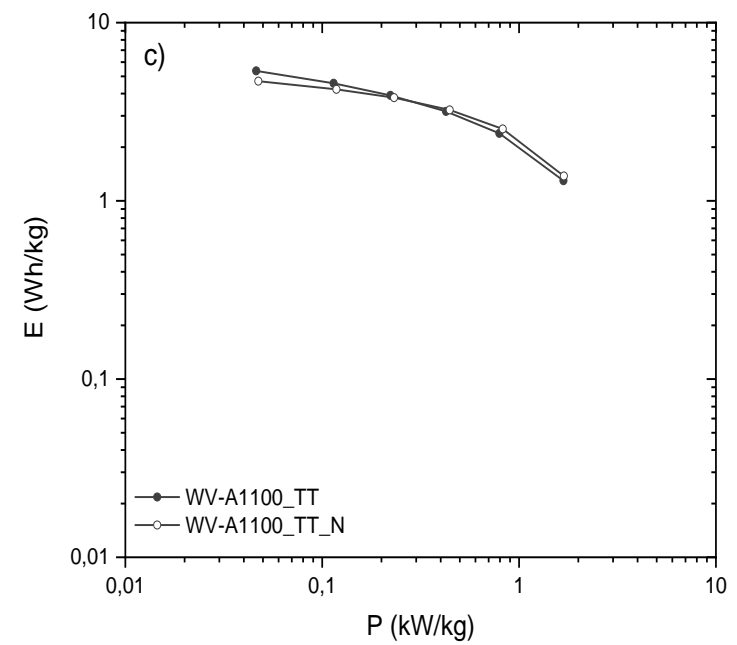

Figure S1. Galvanostatic charge-discharge curves for the symmetric capacitors based on WVA1100_TT and WV-A1100_TT_N at different current densities: (a) $0.1 \mathrm{~A} \mathrm{~g}^{-1}$ and (b) $1 \mathrm{~A} \mathrm{~g}^{-1}$. (c) Ragone plot at $1.1 \mathrm{~V}$ for both symmetric capacitors.

Table S2. Power and energy density values for the symmetric capacitors after durability test by galvanostatic charge-discharge cycles. Electrolyte: $1 \mathrm{M} \mathrm{H}_{2} \mathrm{SO}_{4}$ solution. $\mathrm{j}=0.1 \mathrm{~A} \mathrm{~g}^{-1}$.

\begin{tabular}{cccccc}
\hline Capacitor & $\mathbf{C} / \mathbf{F} \mathbf{~ g}^{-\mathbf{1}}$ & $\mathbf{E} / \mathbf{W h} \mathbf{~ k g}^{-\mathbf{1}}$ & $\mathbf{P} / \mathbf{W} \mathbf{~ k g}^{-1}$ & $\begin{array}{c}\text { Coulombic } \\
\text { Efficiency } \\
(\mathbf{\%})\end{array}$ & $\begin{array}{c}\text { Energy } \\
\text { Efficiency } \\
(\mathbf{\%})\end{array}$ \\
\hline HTC_HR_450_TT & 25 & 2.8 & 28.0 & 70 & 46 \\
HTC_HR_450_TT_N & 28 & 3.3 & 40.3 & 91 & 69 \\
WV-A1100_TT & 34 & 4.5 & 42.1 & 94 & 68 \\
WV-A1100_TT_N & 30 & 4.3 & 45.0 & 97 & 77 \\
\hline
\end{tabular}

Table S3. Power and energy density values of the symmetric capacitors after durability test by galvanostatic charge-discharge cycles. Electrolyte: $1 \mathrm{M} \mathrm{TEMA-BF} / \mathrm{PC}, \mathrm{j}=0.25 \mathrm{~A} \mathrm{~g}^{-1}$.

\begin{tabular}{cccccc}
\hline Capacitor & $\mathbf{C} / \mathbf{F ~ g}^{-\mathbf{1}}$ & $\mathbf{E} / \mathbf{W h} \mathbf{~ k g}^{-\mathbf{1}}$ & $\mathbf{P} / \mathbf{k W} \mathbf{k g}^{-\mathbf{1}}$ & $\begin{array}{c}\text { Coulombic } \\
\text { Efficiency } \\
\mathbf{( \% )}\end{array}$ & $\begin{array}{c}\text { Energy } \\
\text { Efficiency } \\
(\mathbf{\%})\end{array}$ \\
\hline HTC_HR_450 & 18 & 12.2 & 0.24 & 99 & 70 \\
HTC_HR_450_N & 17 & 10.7 & 0.23 & 99 & 70 \\
HTC_HR_450_TT & 19 & 14.1 & 0.26 & 99 & 75 \\
HTC_HR_450_TT_N & 20 & 14.7 & 0.27 & 99 & 79 \\
WV-A1100 & 17 & 12.8 & 0.27 & 99 & 78 \\
WV-A1100_N & 17 & 10.6 & 0.22 & 99 & 62 \\
WV-A1100_TT & 19 & 15.7 & 0.29 & 99 & 84 \\
WV-A1100_TT_N & 20 & 15.7 & 0.27 & 98 & 82 \\
YP50F & 24 & 19.6 & 0.29 & 99 & 85 \\
\hline
\end{tabular}



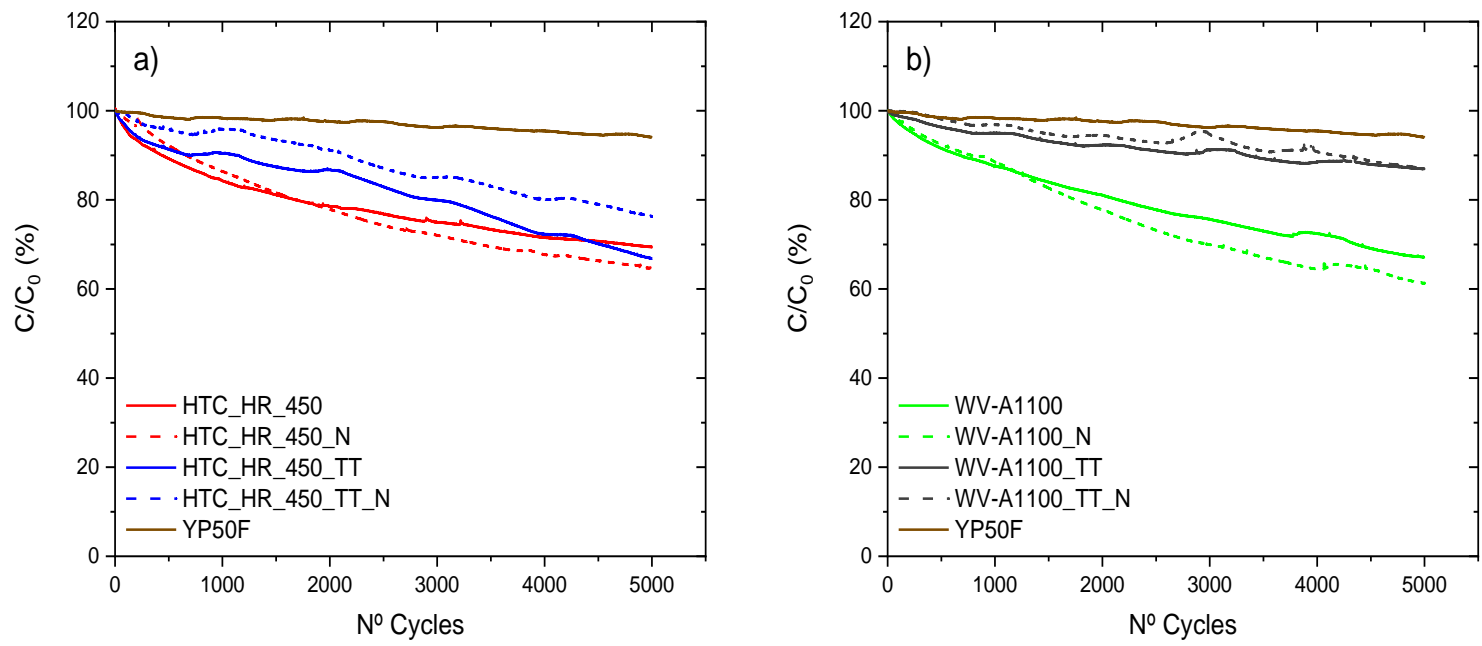

Figure S2. Capacitance retention $\left(\mathrm{C} / \mathrm{C}_{0}\right)$ at $2.5 \mathrm{~V}$ of (a) activated hydrothermal carbon (HTC_HR_450) and the modified counterparts and YP50F (b) WV-A1100 (commercial) and the modified counterparts and YP50F. $\mathrm{j}=1 \mathrm{~A} \mathrm{~g}^{-1}$ (5000 cycles). Electrolyte: $1 \mathrm{M}$ TEMA-BF $/ \mathrm{PC}$ 